\title{
Experimental Investigation of Delamination Growth in Composite Laminates under a Compressive Load
}

\author{
A. Riccio, ${ }^{1}$ R. Cristiano, ${ }^{1}$ G. Mezzacapo, ${ }^{1}$ M. Zarrelli, ${ }^{2}$ and C. Toscano ${ }^{3}$ \\ ${ }^{1}$ Dipartimento di Ingegneria Industriale e dell'Informazione, Università degli Studi della Campania "Luigi Vanvitelli", \\ Via Roma 29, 81031 Aversa, Italy \\ ${ }^{2}$ Institute for Composite and Biomedical Materials, National Research Council (CNR), Portici, Italy \\ ${ }^{3}$ CIRA Italian Aerospace Research Centre, Via Maiorise s/n, Capua, Italy
}

Correspondence should be addressed to A. Riccio; aniello.riccio@unicampania.it

Received 8 February 2017; Revised 19 April 2017; Accepted 2 May 2017; Published 5 July 2017

Academic Editor: Paulo M. S. T. De Castro

Copyright (C) 2017 A. Riccio et al. This is an open access article distributed under the Creative Commons Attribution License, which permits unrestricted use, distribution, and reproduction in any medium, provided the original work is properly cited.

This paper focuses on the use of no-contact experimental techniques for monitoring the interlaminar damage evolution in composite laminates. Indeed, Infrared Thermography and Digital Image Correlation are adopted to investigate, in composite plates with artificial delamination, the influence of the delamination initial position on the delamination growth. The paper also investigates the feasibility of using a no-contact experimental technique for the measurement of displacement and strain during mechanical tests, such as the Digital Image Correlation, to evaluate, by means of indirect measurements, the delamination growth as a function of the applied load.

\section{Introduction}

Carbon fiber reinforced polymer (CFRP) laminates are being studied widely in aerospace and naval application due to their low specific weight and high corrosion resistance with respect to the metallic alloys [1]. However, carbon fiber/epoxy laminates can experience damage formation or imperfections arising during the manufacture and assembly phases or during their service life. Indeed, carbon fiber/epoxy laminates are susceptible to develop, as a consequence of low velocity impacts [2-5], critical damage mechanisms (fiber failure, matrix cracking, and delamination) which are hardly detectable by visual inspection [6-10] and then very dangerous in terms of load carrying capability reduction especially under compressive loading conditions. Moreover, geometrical and material imperfections make the structure prone to the buckling phenomenon, as investigated in [11]. Hence, the study of the compressive behavior of impacted composite structures becomes of main concern for ensuring the fulfilment of integrity and safety structural requirements $[12,13]$.
In order to assess the internal defects and to monitor the damage initiation and propagation in composite structures, widespread experimental techniques are adopted. Among others, Infrared Thermography (IRT) and Digital Image Correlation (DIC), whose combination has been used in [14] to study plastic deformations, can be considered effective and reliable no-contact experimental techniques able to assess the integrity of composite structures. The Infrared Thermography technique is usually adopted to evaluate the temperature field [15-17], while the Digital Image Correlation technique has been found able to satisfy the increasing demand of experimental detailed information connected to a deformation problem [18-23]. The advantages related to these two techniques are the real-time measures, the high precision, and the absence of any contact or interference with the measured samples.

The Infrared Thermography is also used for detection of material defects in structures $[24,25]$ being particularly useful when no-contact inspection is needed, for example, when the investigated structural component is hot and dangerous to inspect with contact sensors or when parts are 
difficult to reach or disconnect or more in general could be damaged by contact. Indeed, the Infrared Thermography is able to reveal heat patterns in the infrared wavelength spectrum, which helps to visualize the damaged elements, using an infrared camera that captures the thermal images in specific ranges of temperatures (i.e., parts of the electromagnetic spectra). Among thermographic techniques, the active approach requires to induce a temperature gradient between the inspected body and the environment, generally warming up or cooling down the material. In the case of the used LockIn method, the component is warmed up by a modulated heat wave while the emitted heat by the component is acquired by the thermal camera and processed by a software whose algorithm is FFT based. [26, 27]. Infrared thermocameras are being continuously developed in terms of both pixel resolution/noise level [28] and Lock-In technique [29] for various applications on solar cells, integrated circuits, and gate oxide integrity defects.

The DIC is one of the most popular no-contact techniques thanks to its ease of implementation, solution accuracy, and cheapness. It is an optical technique, which works by using cameras for recording digital photographs at different loading stages to be compared in order to obtain stress and strain fields. Indeed, according to the DIC technique, random and unique blocks of pixels are tracked to obtain strain and stress measurements.

Many researches have adopted the DIC technique to measure the strain field and the surface displacements in the last years. The local last squares fitting method to calculate the true strain field in presence of holes or crack areas has been investigated in [30] while the detection of strain singularity due to artificial delamination by using the DIC technique has been considered in $[31,32]$. The DIC technique has been used to study the crack growth behavior in [33], the impact induced damage in composite structures under compressive load in [34], and finally, holes in composite laminates and the bonded repairs performance also under tensile load in [35].

In the present paper, the combination of DIC and IRT techniques is used to provide the displacements and the internal damage development in delaminated composite plates during a compressive test. The main aim is to investigate the influence of delamination position on the delamination growth in composite plates. The paper also investigates the feasibility of using the DIC, to evaluate, by means of indirect measurements of strain and displacement fields, the delamination growth as a function of the applied load.

In Sections 2 and 3, the IRT end DIC techniques are, respectively, introduced briefly explaining their working principles. In Section 4, the tested specimen characteristics and the test procedures and setup are presented. Finally, in Section 5, the experimental results are introduced and critically discussed.

\section{Infrared Camera and Lock-In Thermography}

Every object at temperature $T$, greater than the absolute zero (i.e., $T>0 \mathrm{~K}$ ), emits electromagnetic radiations. These radiations mainly fall into the infrared portion of the electromagnetic spectrum. The latter, called also infrared radiations or thermal radiations, propagates from one place to another through the electromagnetic waves. Infrared Thermography offers no-contact fast inspection of extensive areas and can be used as an alternative or complement to other inspection technologies because the infrared imaging device reveals features that are not visible to the naked eye.

Thermography is a nondestructive evaluation (NDE) tool that allows detecting imperfections or characterizing the materials and measuring temperature changes on the material surface due to stress generated thermal fields (SGTF) or externally applied thermal fields (EATF). A sensitive infrared camera, capable of detecting temperature changes less than $0.05 \mathrm{mK}$, is used to detect anomalies in the material heat transfer characteristics related to imperfections.

Materials must be thermally excited to show imperfections. Excitation sources can be applied by external thermal fields or by mechanical tools. In both cases, the produced thermal field depends on the investigated material emissivity. The emissivity, $\varepsilon$, in (1), is defined as the ratio between the thermal radiation, $E$, emitted from a real surface, and the thermal radiation, $E_{B}$, related to a blackbody at the same conditions (temperature, $T$, wavelength, lambda, and direction):

$$
\varepsilon(\lambda, T)=\frac{E(\lambda, T)}{E_{B}(\lambda, T)} .
$$

Infrared detectors are transducers of incident radiant energy. The most used infrared detectors (Figure 1) are

(i) thermal detectors;

(ii) quantum/photon detectors.

They can be classified into cooled and uncooled infrared.

Cooled detectors have to be cooled down under ambient temperature in order to obtain a very rapid scanning rate, high sensitivity, and low thermal noise. The FLIR ${ }^{\mathrm{TM}}$ thermal camera used for this work is provided with a Stirling cycle cooling system. The InSb photovoltaic sensor is effective within the $3 \div 5 \mu \mathrm{m}$ wavelength transmission window, that is, Medium Infrared part of the spectra. Lock-In Thermography is based on the solution of the Fourier equation obtained taking into account the hypothesis that a homogeneous semi-infinite solid body is impinged by a sinusoidal thermal wave of temperature $T$ propagating along $x$ direction with modulation frequency, $\omega$, and initial temperature, $T_{0}$,

$$
T(x, t)=T_{0} e^{-x / \mu} \cos \left(\omega t-\frac{x}{\mu}\right) .
$$

Equation (2) describes the harmonic part of that solution as a thermal wave, with the same modulation frequency as the exciting heat source, delayed by a phase lag $\varphi=x / \mu$ and with an amplitude damped by a factor depending on the socalled diffusion length $\mu=(2 \alpha / \omega)^{1 / 2}$, where $\alpha$ is the thermal diffusivity.

According to the Lock-In Thermography technique, a series of thermal images representing the time evolution of 


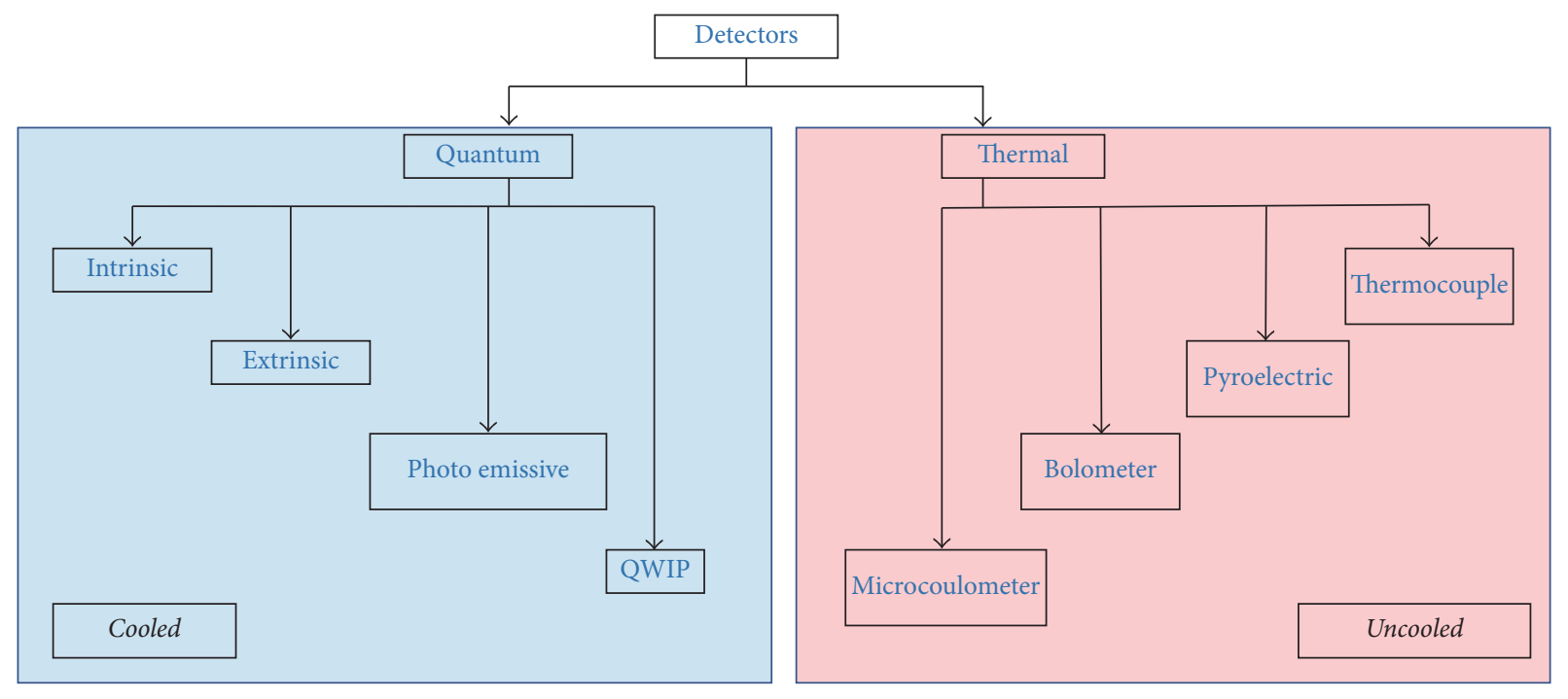

FIgURE 1: Types of IR detectors.

the surface temperature of the inspected body are collected and "compared" with the reference signal given by the excitation thermal wave taken as a reference. So, as in LockIn amplifiers through the FFT the phase lag between the waves as well as the final amplitude can be obtained. From a computational point of view, if the two signals are both of sine-type, the same can be obtained with at least 4 equidistant (or even three) data points per modulation cycle $\left(S_{1}\right.$ to $S_{4}$ in Figure 2) [26].

Therefore, for each pixel, amplitude $A$ (see (3)) and phase $\varphi$ (see (4)) can be calculated by means of already four thermal images taken during one modulation cycle:

$$
\begin{aligned}
& A(x)=\sqrt{\left(S_{3}-S_{1}\right)^{2}+\left(S_{4}-S_{2}\right)^{2},} \\
& \varphi(x)=\operatorname{arctg}\left(\frac{S_{3}-S_{1}}{S_{4}-S_{2}}\right) .
\end{aligned}
$$

From an experimental point of view, the excitation heat source is made by a halogen lamp which emits light modulated by a function generator. So it is possible to choose the frequency and the amplitude of the heat source. Both the reference signal and the heat reemitted by the inspected body are acquired by the thermal camera. The Lock-In software provides two maps in false colour related to $A$ and $\varphi$. The phase maps are particularly interesting due to the possibility of investigating deeper within the thickness of the specimen; the smaller the frequency is the deeper it probes. Since the phase is dependent also on $\mu$, if the body has local discontinuities with different thermal response they will give different phase values, easily represented onto the phase maps with different colours with respect to the surrounding areas.

\section{Digital Image Correlation}

The DIC technique uses a couple of digital cameras for capturing stereoimages related to the examined structure

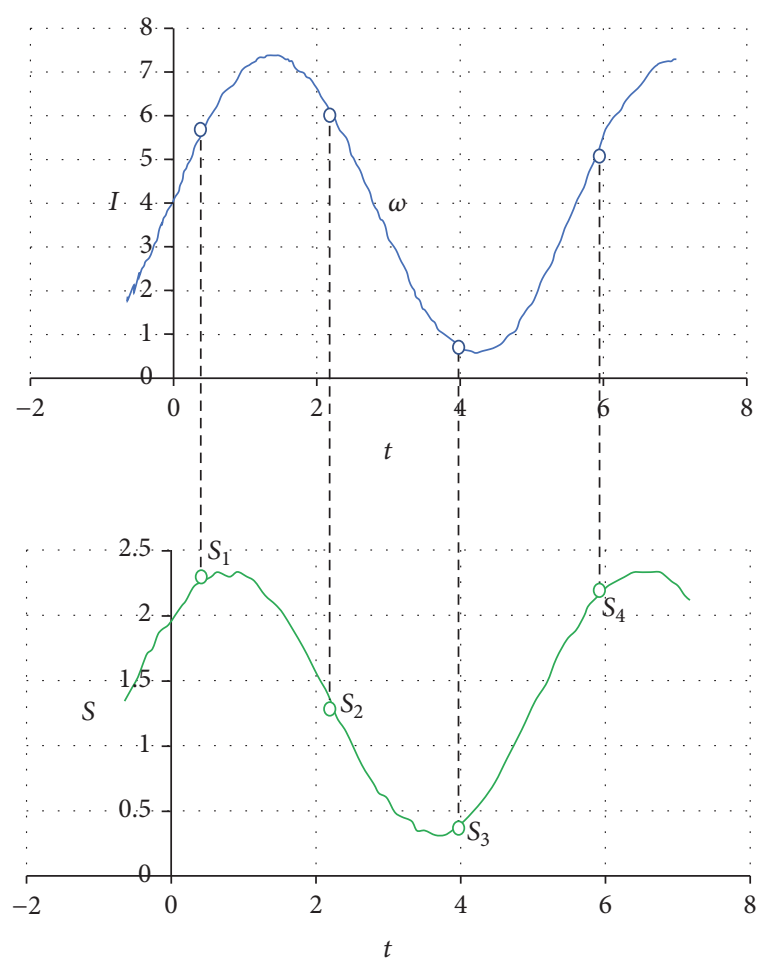

Figure 2: Amplitude and phase obtained by a sinusoidal thermal excitation.

under different loading conditions and so it allows estimating the unknown displacement (also out of the plane) and strain fields by comparing the recorded images to the initial nondeformed configuration [36]. The main DIC benefit is the capability of analyzing large displacements and deformations areas with no need of attaching sensors if compared with the conventional measuring methods. 


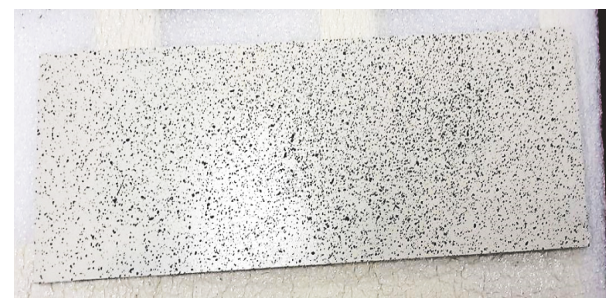

FIGURE 3: Specimen preparation for DIC.

Figure 3 shows the specimen's surface preparation for DIC application. The surface is marked with a black dots pattern on a white background to increase the capability to distinguish locations on the specimen surface. Indeed, the black dots have to be absolutely randomly positioned and of random size, depending on the specimens' dimensions. The images of the specimens, acquired during testing, are elaborated by splitting the surface and the pattern in many subsets. 50 substeps with step 2-3 and strain gauge length of $1 \mathrm{~mm}$ were automatically selected by the VIC 3D device in order to minimize the influence on the displacement and strain field, according to the selected region of interest and to the random black dot size and position.

The black pattern on a white background is conceived to make easier and quicker the algorithm work in recording and elaborating the captured images. Indeed, integer values from 0 (black) to 100 (white), according to the current gray gradation, within the pattern are used. During the test, the pattern substep will move to a new position and the software is able to recognize this new position for the displacement calculation. This process is described in Figure 4.

In order to evaluate the displacement field, a correlation method is needed. There are three main correlation methods, which belong to the sum of squared differences criteria group. All the suggested criteria are used to evaluate the displacements. The strains field is evaluated by derivatives of the computed displacement field.

\section{(i) Sum of Squared Differences Criterion}

$$
C_{\mathrm{SSD}}=\sum_{i}^{N} \sum_{j}^{N}\left[f\left(x_{i}, y_{i}\right)-g\left(x_{i}^{\prime}, y_{i}^{\prime}\right)\right]^{2},
$$

where $f$ and $g$ are the values before and after the motion, $\left(x_{i}, y_{i}\right)$ are the pixel coordinate in the reference image before the motion, and $\left(x_{i}^{\prime}, y_{i}^{\prime}\right)$ are the pixel coordinate in the reference image after the motion. It is a particularly fast criterion, even if it is not very robust because it is very sensitive to brightness changes.

(ii) Normalized Sum of Squared Differences Criterion

$$
C_{\mathrm{NSSD}}=\sum_{i}^{N} \sum_{j}^{N}\left[\frac{f\left(x_{i}, y_{i}\right)}{\bar{f}}-\frac{g\left(x_{i}^{\prime}, y_{i}^{\prime}\right)}{\bar{g}}\right]^{2}
$$

with

$$
\begin{gathered}
\bar{f}=\sqrt{\sum_{i}^{N} \sum_{j}^{N}\left[f\left(x_{i}, y_{i}\right)\right]^{2}}, \\
\bar{g}=\sqrt{\sum_{i}^{N} \sum_{j}^{N}\left[g\left(x_{i}^{\prime}, y_{i}^{\prime}\right)\right]^{2}} .
\end{gathered}
$$

This criterion seems to be more robust than the previous one because it is not sensitive to the brightness scale variation.

(iii) Zero-Normalized Sum of Squared Differences Criterion

$$
C_{\mathrm{ZNSSD}}=\sum_{i}^{N} \sum_{j}^{N}\left[\frac{f\left(x_{i}, y_{i}\right)-f_{m}}{\Delta f}-\frac{g\left(x_{i}^{\prime}, y_{i}^{\prime}\right)-g_{m}}{\Delta g}\right]^{2}
$$

with

$$
\begin{aligned}
& \Delta f=\sqrt{\sum_{i}^{N} \sum_{j}^{N}\left[f\left(x_{i}, y_{i}\right)-f_{m}\right]^{2}}, \\
& \Delta g=\sqrt{\sum_{i}^{N} \sum_{j}^{N}\left[g\left(x_{i}^{\prime}, y_{i}^{\prime}\right)-g_{m}\right]^{2}},
\end{aligned}
$$

where $f_{m}$ and $g_{m}$ are the average gray values of the respective subset. This is the most robust formulation because it is not sensitive to both brightness scale and brightness changes [26].

In order to correctly evaluate the displacements and the strains, it is necessary to know the specimen position according to a $3 \mathrm{D}$ scanning system. The camera parameters and relative orientation should be also calibrated to extract the specimen position in the chosen reference coordinate system by means of an arbitrary calibrated rigid target (white grid with equally spaced black dots in Figure 5).

The target does not need to be exactly flat (even if a rather flat calibration target is adopted), but the distance between two points has to be clearly known. In order to guarantee the grid covering the entire image, in particular close to the boundaries, distortions become really important. These distortions are calibrated by short lenses which require a substantial number of images.

\section{Tested Specimen and Test Procedures Description}

4.1. Tested Specimen Description. As already mentioned, the IRT and DIC techniques have been used to track damage propagation and strain/displacements fields in delaminated composite plates.

The tested specimens are composite plates made of G1157/RTM6 material. The material properties have been evaluated by means of a full experimental material characterization campaign performed by CNR (Italian National Research Council). The system plies have been arranged according to the stacking sequence $[0,90,90,0]_{4 S}$. An artificial circular delamination with $40 \mathrm{~mm}$ diameter has been 


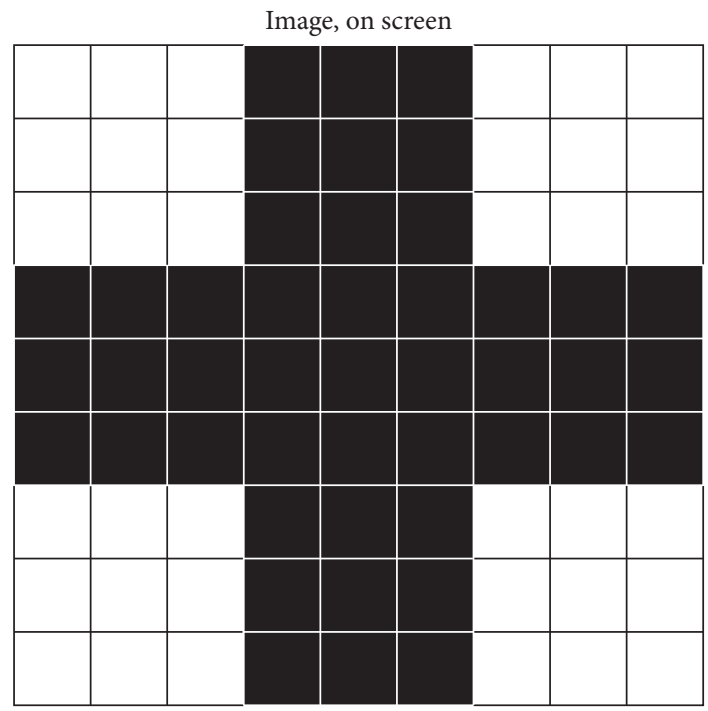

\begin{tabular}{|c|c|c|c|c|c|c|c|c|}
\hline 100 & 100 & 100 & 0 & 0 & 0 & 100 & 100 & 100 \\
\hline 100 & 100 & 100 & 0 & 0 & 0 & 100 & 100 & 100 \\
\hline 100 & 100 & 100 & 0 & 0 & 0 & 100 & 100 & 100 \\
\hline 0 & 0 & 0 & 0 & 0 & 0 & 0 & 0 & 0 \\
\hline 0 & 0 & 0 & 0 & 0 & 0 & 0 & 0 & 0 \\
\hline 0 & 0 & 0 & 0 & 0 & 0 & 0 & 0 & 0 \\
\hline 100 & 100 & 100 & 0 & 0 & 0 & 100 & 100 & 100 \\
\hline 100 & 100 & 100 & 0 & 0 & 0 & 100 & 100 & 100 \\
\hline 100 & 100 & 100 & 0 & 0 & 0 & 100 & 100 & 100 \\
\hline
\end{tabular}

(a)

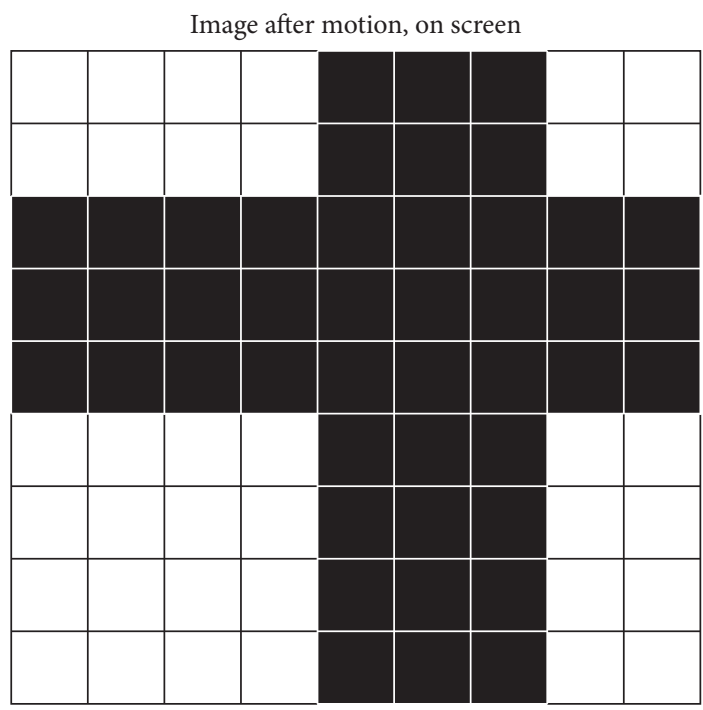

\begin{tabular}{|c|c|c|c|c|c|c|c|c|}
\hline 100 & 100 & 100 & 100 & 0 & 0 & 0 & 100 & 100 \\
\hline 100 & 100 & 100 & 100 & 0 & 0 & 0 & 100 & 100 \\
\hline 0 & 0 & 0 & 0 & 0 & 0 & 0 & 0 & 0 \\
\hline 0 & 0 & 0 & 0 & 0 & 0 & 0 & 0 & 0 \\
\hline 0 & 0 & 0 & 0 & 0 & 0 & 0 & 0 & 0 \\
\hline 100 & 100 & 100 & 100 & 0 & 0 & 0 & 100 & 100 \\
\hline 100 & 100 & 100 & 100 & 0 & 0 & 0 & 100 & 100 \\
\hline 100 & 100 & 100 & 100 & 0 & 0 & 0 & 100 & 100 \\
\hline 100 & 100 & 100 & 100 & 0 & 0 & 0 & 100 & 100 \\
\hline
\end{tabular}

(b)

Figure 4: (a) Grayscale values (nondeformed configuration). (b) Grayscale values (deformed configuration).

placed between the second and the third ply by means of a Teflon insert during manufacturing with a negligible thickness. In this paper only one thickness $(t)$ and one radius $(R)$ values have been examined. Further studies could evaluate the thickness and the delamination radius changes influence. Two geometrical configurations with central and side delamination have been tested. The geometrical configuration is described in Figure 6 while the geometrical description of the tested specimens and the properties of the material system are presented in Tables 1 and 2, respectively.

Figure 7 shows phase maps taken from a preliminary IRT inspection on the two delaminated panels in order to detect the artificial defect.

The infrared camera and the DIC cameras are placed framing, respectively, the opposite sides of the same specimen. This caution is due to the presence of the black and white pattern on one side of the sample, which could be responsible for an emissivity degradation of the surface, making IRT less effective. First, the thinner sublaminate has been analyzed as shown in Figure 8.

The DIC and the IR measurements have been carried out simultaneously. Indeed, the heat from the lighting system of the DIC optical setup is negligible if compared to the heat from the halogen lamps used during Lock-In Thermography inspection. Hence, it has been easily verified during the tests.

In order to investigate the influence of the delamination position on the compressive mechanical behavior of the specimen, including delamination growth, the specimen has been subjected to an increasing compressive axial displacement. The compressive displacement has been applied in steps. In order to check for delamination growth, the IRT test has been performed at the end of each load step by 


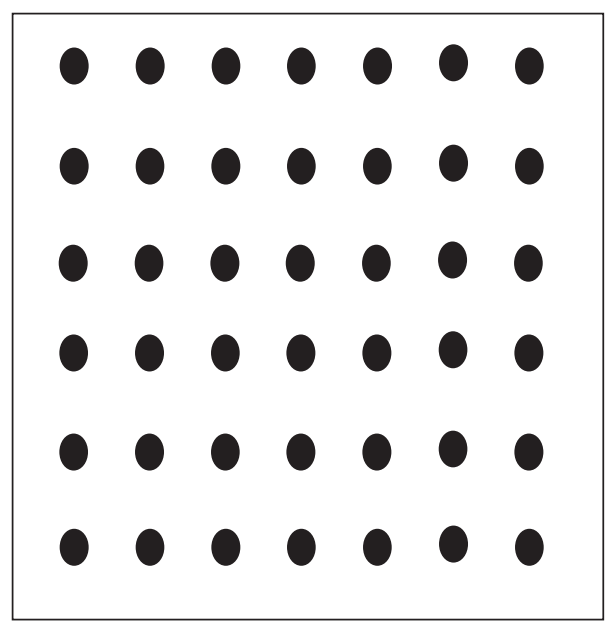

FIGURE 5: Example of the calibration grid.
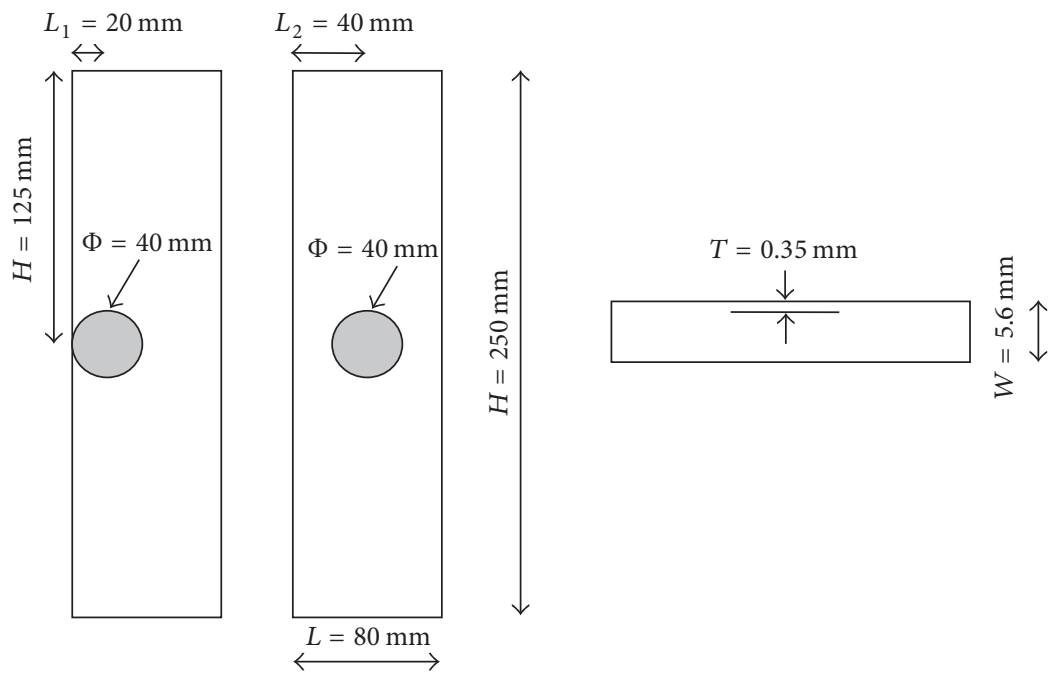

FIGURE 6: Geometrical description of the two tested specimens.

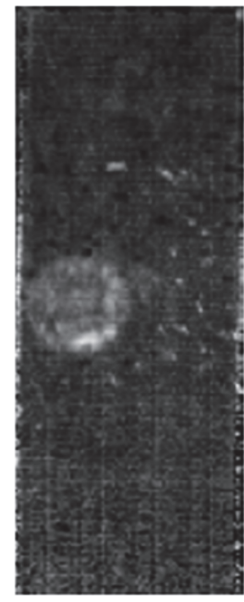

(a)

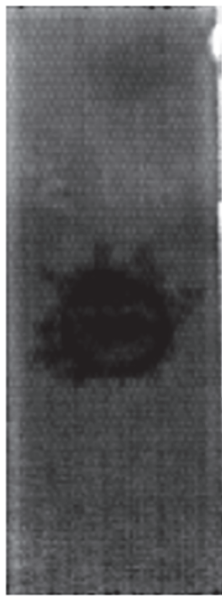

(b)

FIgURE 7: Two specimens' initial delamination position; (a) side delamination; (b) central delamination. 


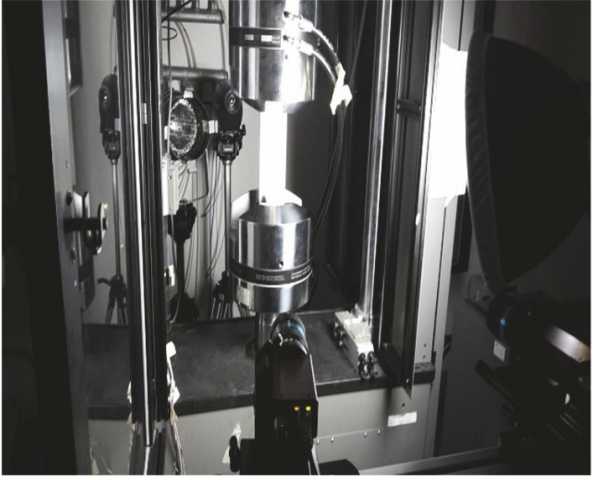

(a)

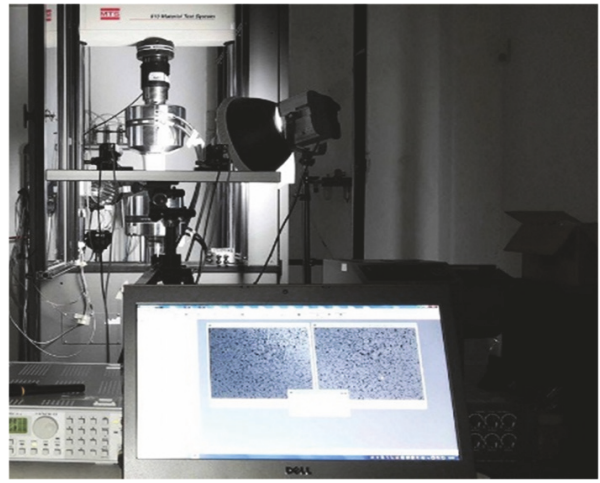

(b)

FIGURE 8: IRF and DIC test setup; (a) IRT and DIC cameras on the opposite side of the tested specimen; (b) complete test setup.

TABLE 1: Geometrical description of the tested specimens.

\begin{tabular}{lc}
\hline Specimens height $(H)$ & $250 \mathrm{~mm}$ \\
Specimens length $(L)$ & $80 \mathrm{~mm}$ \\
Specimens width $(W)$ & $5.6 \mathrm{~mm}$ \\
Delamination position through the & $0.35 \mathrm{~mm}$ \\
thickness $(t)$ & $125 \mathrm{~mm}$ \\
Delamination position in plan $(h)$ & $20 \mathrm{~mm}$ \\
Delamination position in plan $(L 1)$ & $40 \mathrm{~mm}$ \\
Delamination position in plan $(L 2)$ & $40 \mathrm{~mm}$ \\
Delamination diameter $(\Phi)$ & $45 \mathrm{~mm}$ \\
Specimens landing lengths & \\
\hline
\end{tabular}

TABLE 2: Material properties.

\begin{tabular}{|c|c|}
\hline Properties & Value \\
\hline Ply thickness & $0.175 \mathrm{~mm}$ \\
\hline Elastic properties & $\begin{array}{l}E_{1}=130.05 \mathrm{GPa} ; E_{2}=E_{3}=11.55 \mathrm{GPa} ; G_{12}=G_{13} \\
\quad=G_{23}=6 \mathrm{GPa} ; v_{12}=v_{13}=0.312 ; v_{23}=0.48 ;\end{array}$ \\
\hline Strength $[\mathrm{MPa}]$ & $\begin{array}{c}X_{t}=1460.7 \mathrm{MPa} ; X_{c}=876.42 \mathrm{MPa} ; Y_{t}=Z_{t}= \\
77.145 \mathrm{MPa} ; Y_{c}=Z_{c}=241.43 \mathrm{MPa} ; S_{12}=S_{13}= \\
30 \mathrm{MPa} ; S_{23}=40 \mathrm{MPa}\end{array}$ \\
\hline Fracture toughness & $G_{I c}=180 \mathrm{~J} \times \mathrm{m}^{-2} ; G_{I I c}=G_{I I I c}=500 \mathrm{~J} \times \mathrm{m}^{-2}$ \\
\hline
\end{tabular}

pausing the loading process without unloading the specimen. Then the specimen is unloaded and a new step is started, applying an increasing level of displacement. On the other hand, during the same experimental analysis, the DIC test has been performed continuously by recording every out-ofplane surface displacement of the specimen when increasing the load within each step. The adopted infrared camera is a FLIR silver SC5500, while the DIC has been performed by using the VIC-3D ${ }^{\mathrm{TM}}$ system provided with two high resolution cameras. The compression test has been carried out using the 810 Material Testing System (MTS) hydraulic machine in a statistical regime. The test has been performed setting the parameters reported in Table 3.
TABLE 3: Test parameters.

\begin{tabular}{lc}
\hline DIC & $1 \mathrm{~Hz}$ (1 image per second) \\
Infrared camera (frame frequency) & $103 \mathrm{~Hz}$ \\
Lamp (heat excitation frequency) & $0.5 \mathrm{~Hz}$ \\
LOA velocity & $0.3 \mathrm{~mm} / \mathrm{min}$ (compression) \\
\hline
\end{tabular}

TABLE 4: Load conditions for the side delamination.

\begin{tabular}{lcc}
\hline Step & Displacement $[\mathrm{mm}]$ & Load $[\mathrm{kN}]$ \\
\hline 1 & 0.61 & -40 \\
2 & 0.645 & -42.2 \\
3 & 0.76 & -42.7 \\
4 & 0.83 & -42.7 \\
5 & 0.9 & -42.4 \\
6 & 1.03 & $-41.9 \rightarrow-41.5$ \\
7 & 1.13 & $-41.1 \rightarrow-40.6$ \\
8 & 1.2 & $-40 \rightarrow-39.5$ \\
9 & 1.75 & $-29 \rightarrow-25$ \\
\hline
\end{tabular}

\section{Experimental Results}

As already mentioned, in order to be able to investigate the delamination growth during the compressive test, the test has been performed by applying 9 increasing levels of displacement, as shown in Tables 4 and 5 for the specimen with side and central delamination.

At the end of each load step, without unloading the specimen, the Lock-In method is applied to check for the delamination growth by observing edges modification of the artificial defect onto the phase maps. Then the specimen is unloaded and a new step is performed up to the next level of displacement. On the other hand the DIC has been performed continuously during each loading step when applying the compressive displacement.

Figures 9 and 10 show the force-displacement curves, obtained at each step, respectively, for the specimen with side and central delamination. The slope reduction passing 


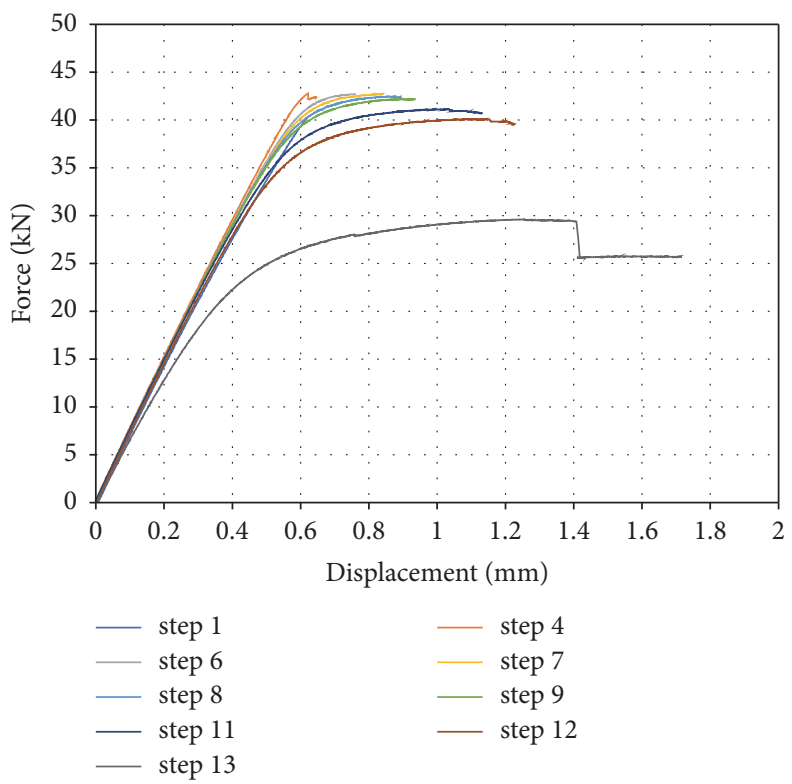

FIGURE 9: Force-displacement curves for the side delamination.

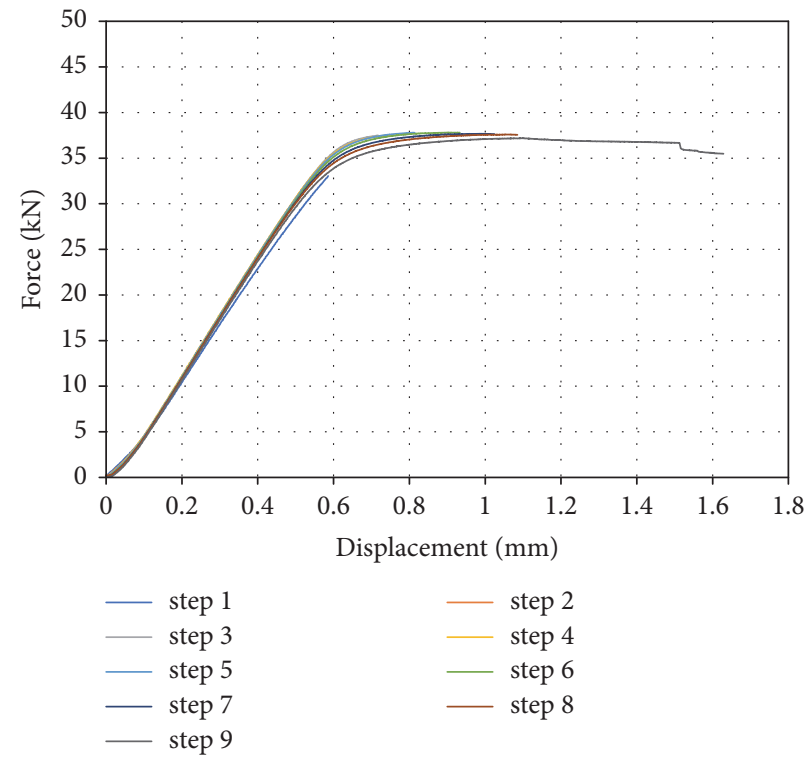

Figure 10: Force-displacement curves for the central delamination.

from one step to the next can be considered representative of the damage evolution experienced by the specimens during compression.

From Figures 9 and 10, both the specimens experience the buckling phenomenon leading to a constant value of the load while increasing the compressive displacements. The side delamination appears to be clearly affected by a reduction of the stiffness between one step and another with a clear decrease of the buckling load value. On the other hand, the specimen with central delamination seems to be not affected by stiffness or buckling load reduction from one step to another for all the performed compressive steps up to specimen failure.
Figures 11 and 12 show the DIC contour plot of the surface strain in the loading direction, respectively, for the specimen with side and central delamination at the end of the loading step. These images have been taken from the thicker sublaminate side. It is worth noting that all the DIC measurements have been taken in a $4000 \times 4000$ pixels $(100$ pixels $=1 \mathrm{~mm})$ windows centered with respect to the specimen center. In a cyclic experimental test the variation of the local strain field distribution could be of course associated with localized damage effects. However, this phenomenon has been not analyzed because out of the scope of the present paper. Future works could be focused on the correlation between local damage and strain distribution. 


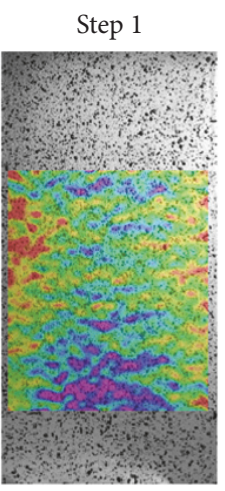

Max 930 Min -2055

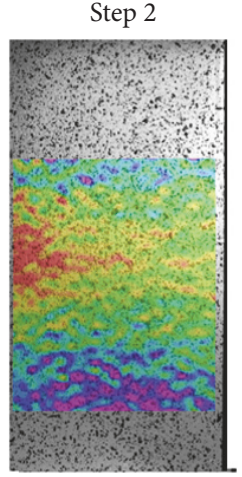

Max 1302.5

Min -3160
Step 5

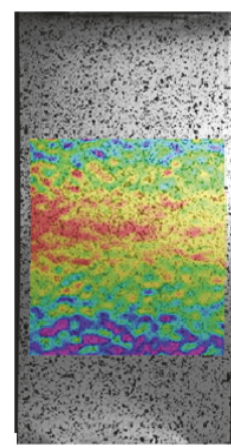

$\operatorname{Max} 3535$

Min -3800
Step 6

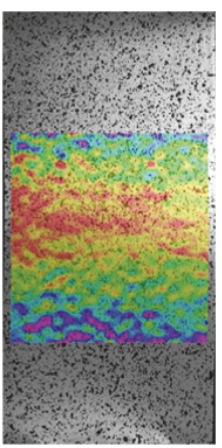

$\operatorname{Max} 6650$

Min -3550
Step 8

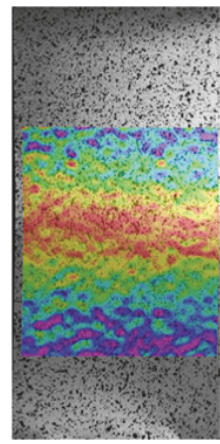

Max 9600

Min -5400
Step 9

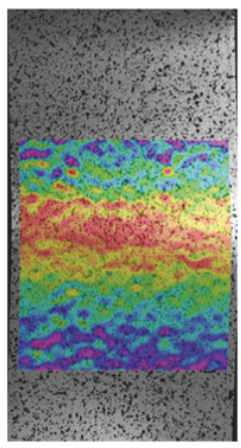

$\operatorname{Max} 13000$

Min -7100

FIGURE 11: Surface strain-principal step-side delamination specimen $[\mu \varepsilon]$.
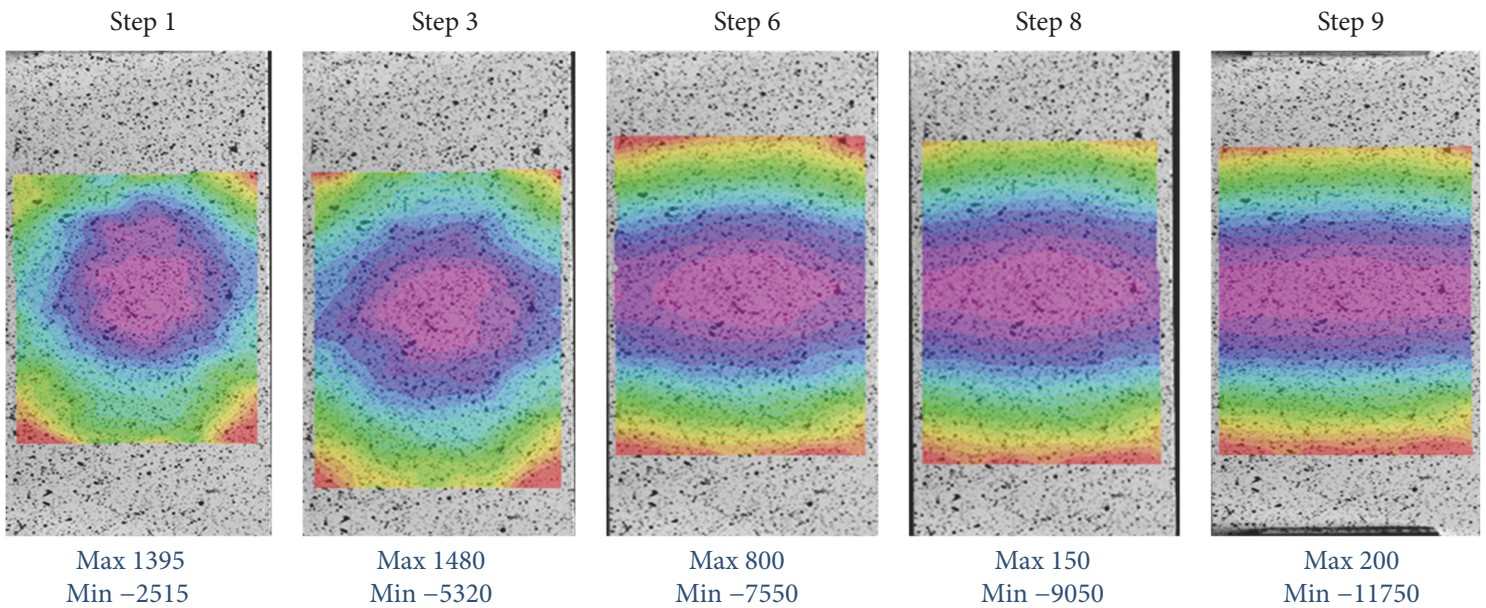

FIGURE 12: Surface strain-principal step-central delamination specimen $[\mu \varepsilon]$.

TABLE 5: Load conditions for the central delamination.

\begin{tabular}{lcc}
\hline Step & Displacement $[\mathrm{mm}]$ & Load $[\mathrm{kN}]$ \\
\hline 1 & 0.61 & -33.75 \\
2 & 0.645 & -35.4 \\
3 & 0.76 & -38.13 \\
4 & 0.83 & -38.3 \\
5 & 0.9 & -38.45 \\
6 & 1.03 & -38.3 \\
7 & 1.13 & -38.3 \\
8 & 1.2 & $-38.3 \rightarrow-38$ \\
9 & 1.75 & $-37.9 \rightarrow-36$ \\
\hline
\end{tabular}

The influence of delamination position on the strain distribution can be clearly observed in Figures 11 and 12 at the end of the first load steps. Indeed, increasing the applied displacement from one step to another the global buckling shape can be clearly distinguished.

The DIC surface strain distributions are plotted for each step along $x$ and $y$ symmetry axes for the specimen with side and central delamination, respectively, in Figures 13 and 14. The considerations made for Figures 11 and 12 apply.

The DIC out-of-plane displacements contours for both the studied specimens at the end of the loading steps are shown in Figures 15 and 16.

The effect of local delamination buckling on the out-ofplane displacements for the side delamination can be appreciated from the first steps images reported in Figure 15. On the other hand, Figure 16 shows that the central delamination buckling profile can be hardly distinguished from the first steps images.

The effects of the global buckling of the specimen on the out-of-plane displacements distribution can be observed from the last step images for both configurations. It is worth noting that, under compressive load, the two tested specimens undergo different deformed buckling shapes. Indeed, the specimen with side delamination buckles in the opposite direction with respect to thinner sublaminate while the central delaminated specimen buckles toward the direction of the thinner sublaminate.

The DIC out-of-plane displacements distributions are plotted for each step along $x$ and $y$ axes for the specimen with 

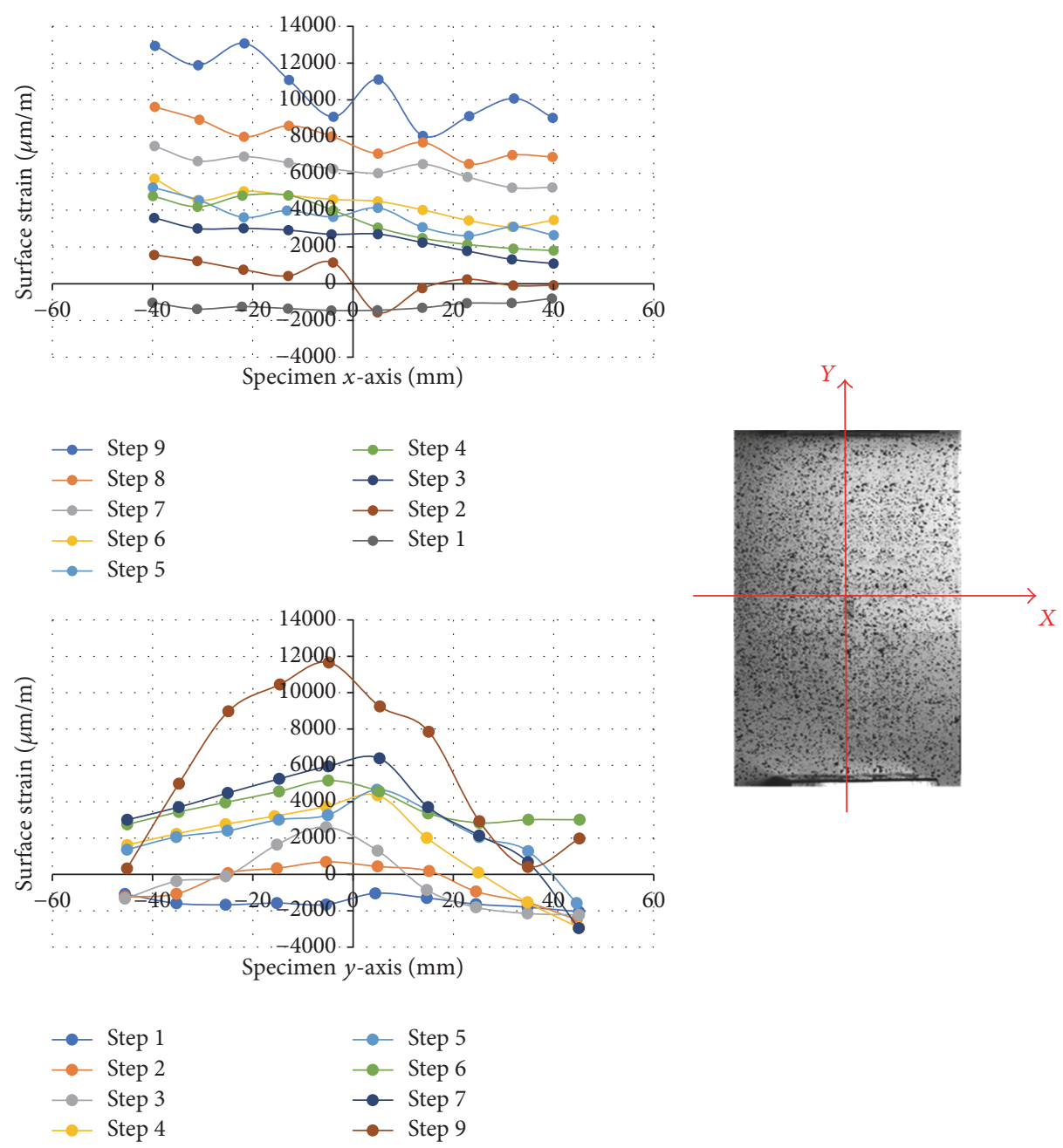

FIGURE 13: Surface strain-principal values along symmetry axes-side delamination specimen.

side and central delamination, respectively, in Figures 17 and 18. The considerations made for Figures 15 and 16 apply.

Tridimensional representations of the out-of-plane displacement distributions obtained with the DIC are presented in Figures 19 and 20, respectively, for the specimen with side and central delamination.

In these figures a comparison between the tridimensional distributions of the out-of-plane displacements obtained at the end of the first step and at the end of the last step is introduced. As it can be observed in Figure 19, even if the noise level is quite relevant in the first step images, the influence of the side positioned delamination on the out-of-plane displacements of the specimen is clearly distinguishable. The same cannot be said for Figure 20 where the central buckling delamination profile seems not to be completely developed. The global buckling profile is, again, clearly observable for both the specimen configurations. The difficulty in detecting the local buckling of delamination is due to the position of the DIC apparatus. Indeed the DIC apparatus, as already mentioned, has been located on the thicker sublaminate side. Hence, all we can appreciate from this position is the effect of the delamination buckling on the global out-of-plane and strain distributions of the specimen. The effect of delamination buckling on the global strain and displacement distributions seems to be more relevant for the side delamination with respect to the central delamination.

The Lock-In method has allowed evaluating the delamination growth during the compressive static tests.

The delamination evolution as a function of the increasing compressive load is shown in the following phase maps. In Figure 21 the specimen with side delamination is shown as a circular red shape juxtaposed to blue background and in Figure 22 the phase maps of the specimen with the central delamination can be seen (also in this case as circular red shape on a blue background).

Figure 21 shows that the side delamination specimen is interested by a relevant delamination growth. Indeed, the side delamination area grows from $1256 \mathrm{~mm}^{2}$ to $2045 \mathrm{~mm}^{2}$ from the first step up to the specimen failure. On the other hand, Figure 22 shows that the central delamination growth is almost negligible (central delamination area, from the first step up to the specimen failure, grows from $1256 \mathrm{~mm}^{2}$ to $1471 \mathrm{~mm}^{2}$ ). This behavior can be explained by the different global buckling shape in terms of out-of-plane 

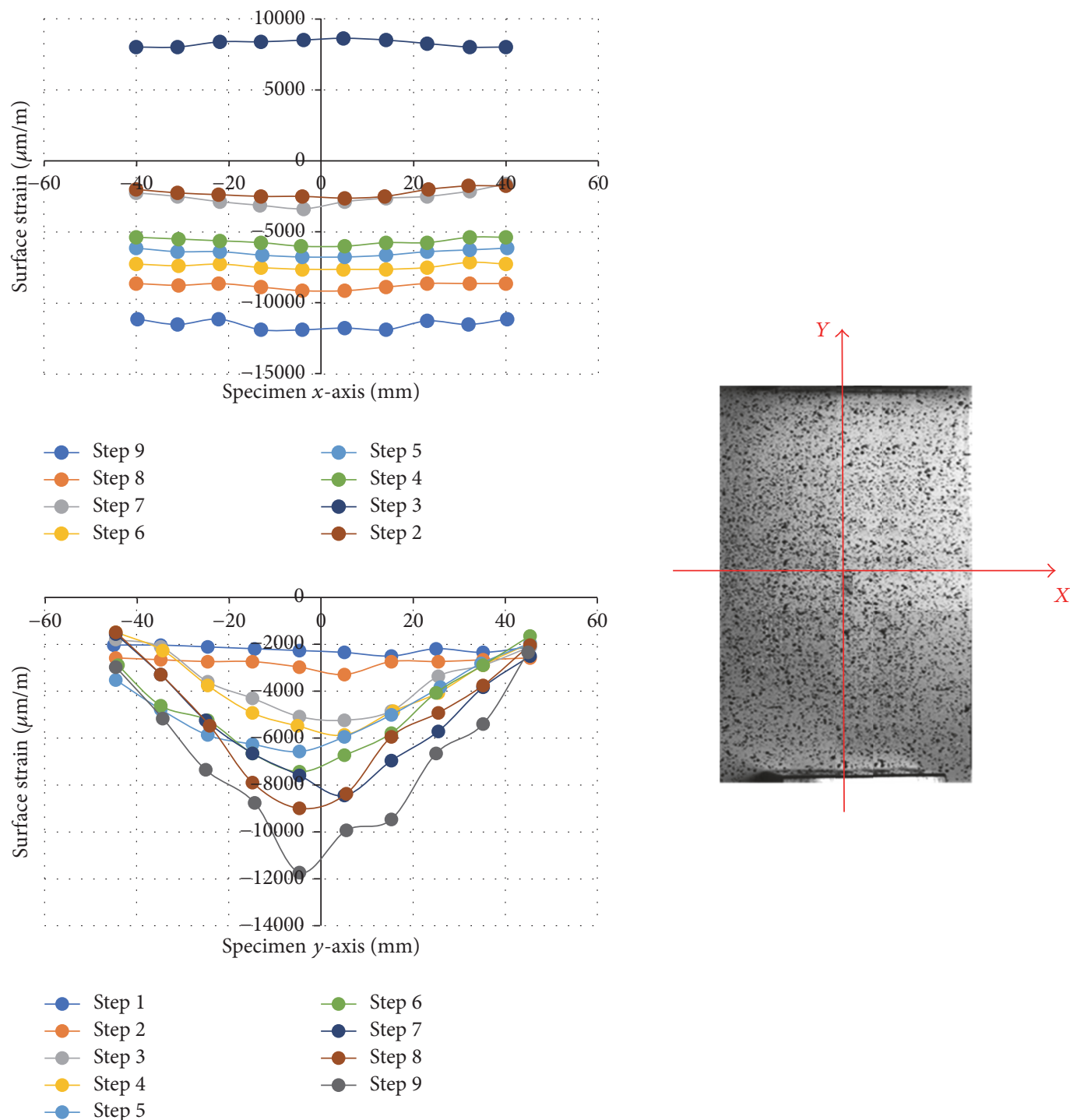

FIGURE 14: Surface strain-principal values along symmetry axes-central delamination specimen.

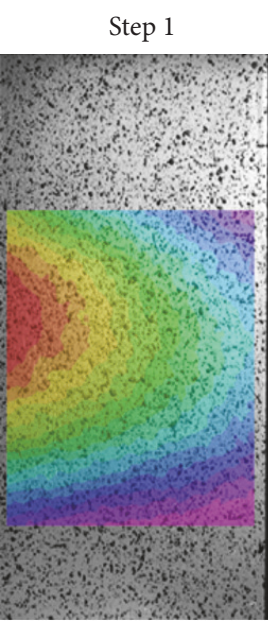

Max 422

Min 152

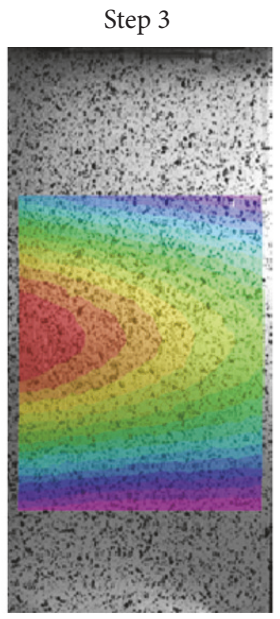

Max 3500 Min 1500

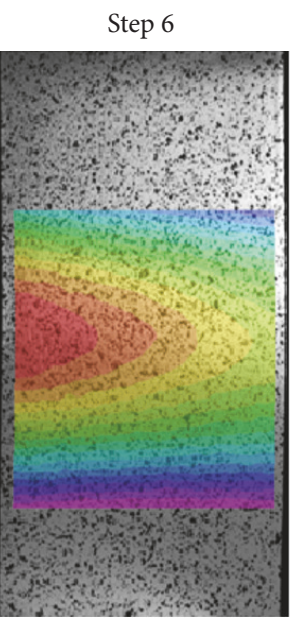

Max 5640

Min 3040
Step 8

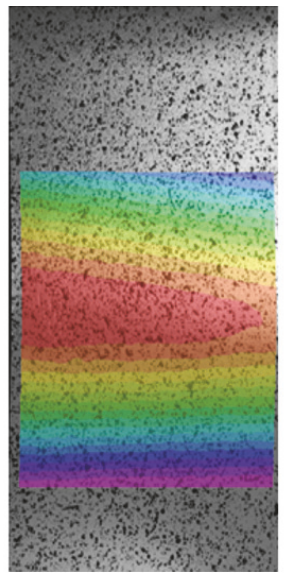

Max 6800

Min 2920

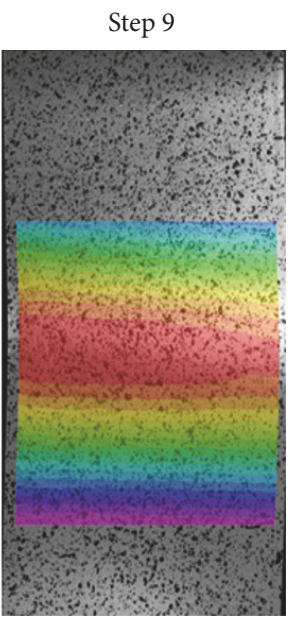

Max 8720

Min 3820

FIGURE 15: Out-of-plane displacement-principal step-side delamination specimen $[\mu \varepsilon]$. 


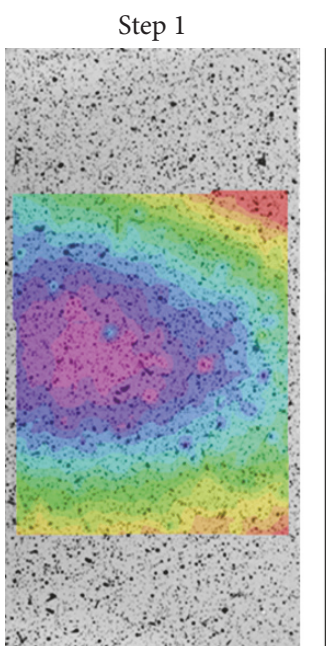

Max -226
Min -708
Step 3

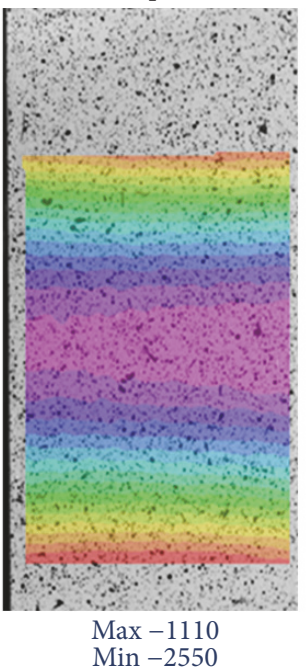

Step 6

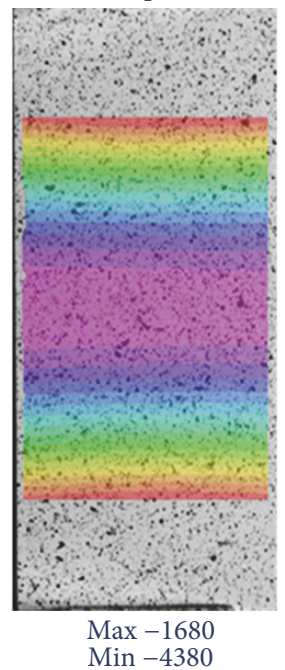

Step 9

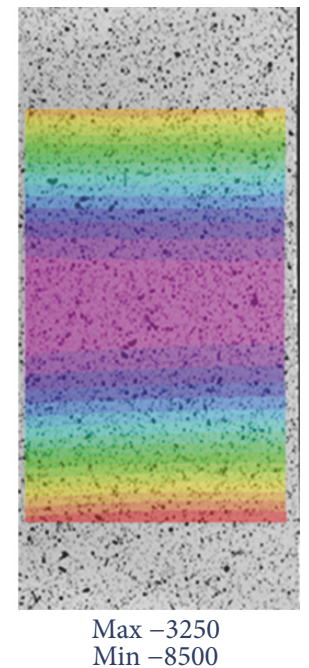

FIGURE 16: Out-of-plane displacement-principal step-central delamination specimen $[\mu \varepsilon]$.

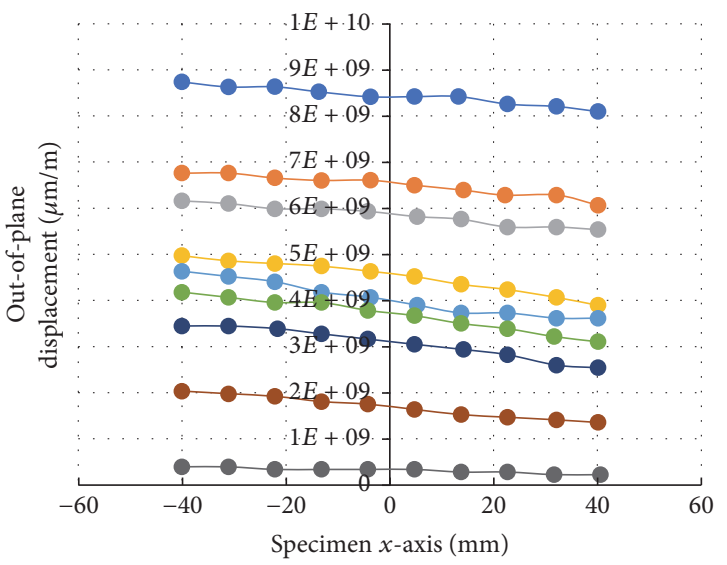

$$
\begin{array}{ll}
\longrightarrow \text { Step } 9 & - \text { Step } 4 \\
- \text { Step } 8 & - \text { Step 3 } \\
- \text { Step } 7 & - \text { Step 2 } \\
- \text { Step 6 } & - \text { Step 1 } \\
- \text { Step } 5 &
\end{array}
$$
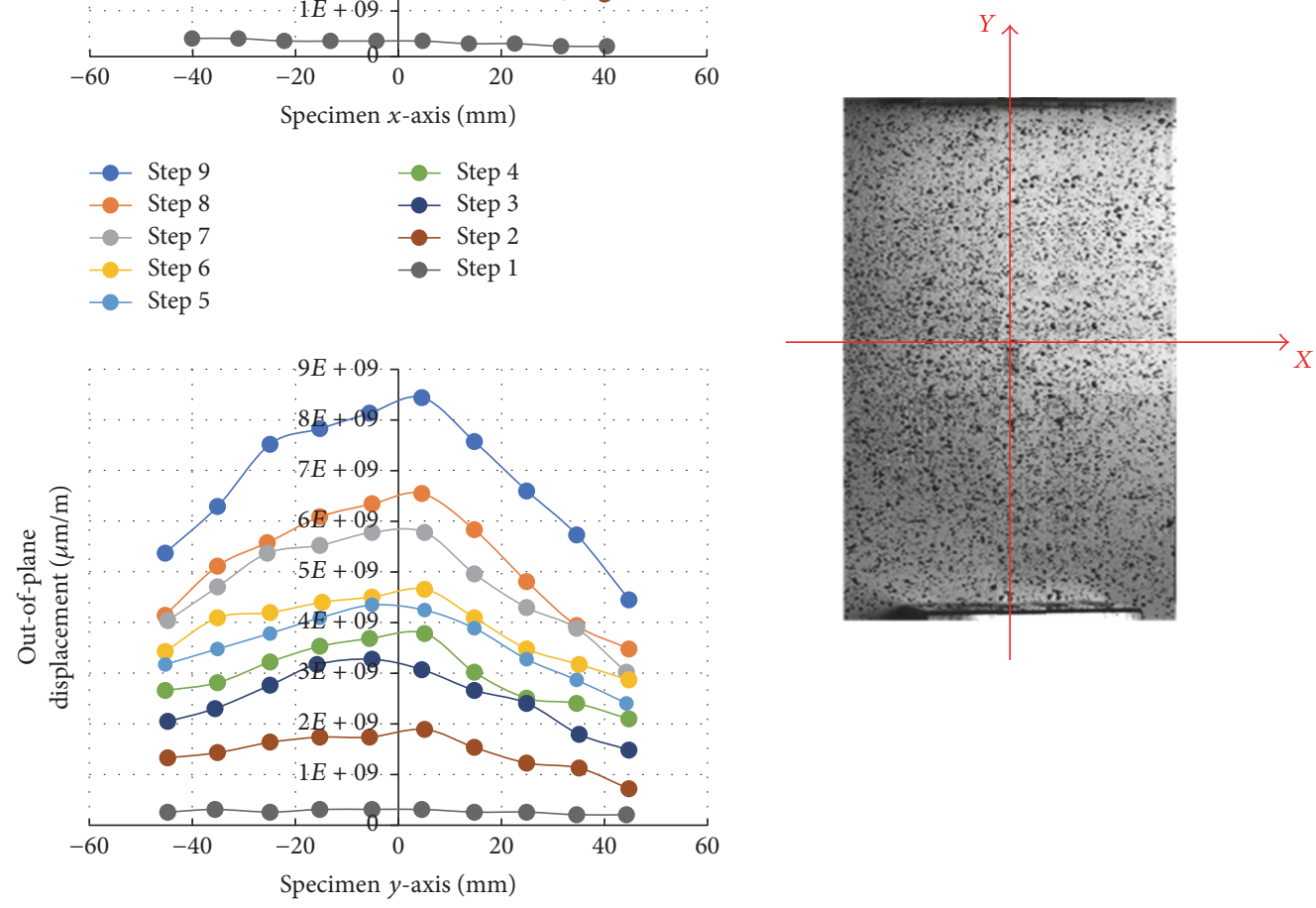

$$
\begin{aligned}
& \begin{array}{ll}
- \text { Step } 9 & - \text { Step } 4 \\
- \text { Step } 8 & - \text { Step } 3
\end{array} \\
& \text { - Step } 7 \quad-\text { Step } 2 \\
& \text { - Step } 6 \quad-\text { Step } 1 \\
& \text { - Step } 5
\end{aligned}
$$

FIGURE 17: Out-of-plane displacement values along symmetry axes-side delamination specimen. 

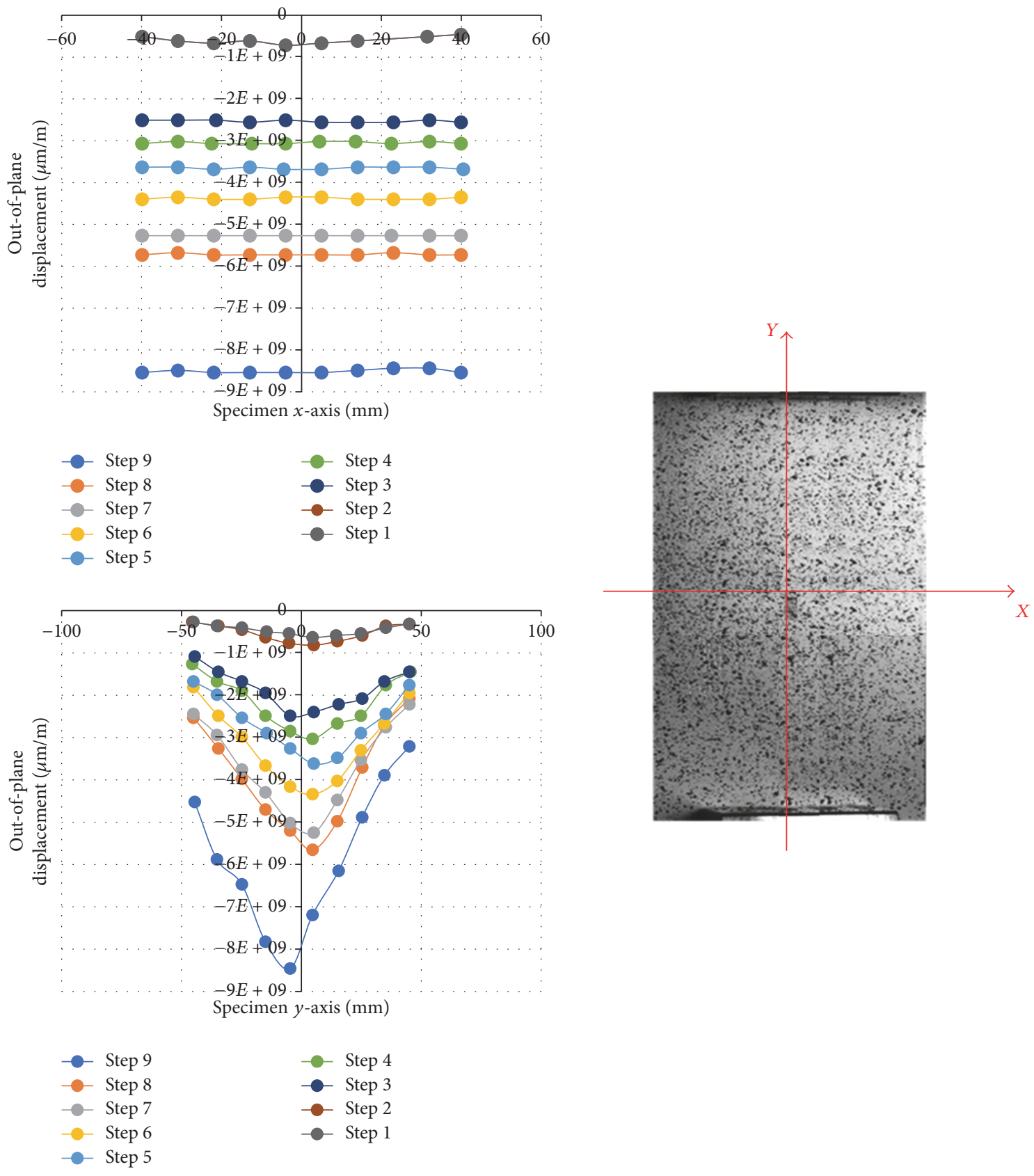

Figure 18: Out-of-plane displacement values along symmetry axes-central delamination specimen.

direction observed for the two specimens. Indeed, for the side delamination specimen, the thinner sublaminate is under compression and the local buckling turns out to be a natural consequence. For the central delamination specimen, the thinner sublaminate is under traction, and hence it is not prone to the local buckling. The growth trend as a function of the applied compressive displacements, for the two types of delamination, is reported in Figure 23. For this figure, the differences in terms of growth between the two analyzed configurations can be clearly noticed. Indeed, for the side delamination, a constant growth can be appreciated with a sudden increase of delamination size at the global buckling displacement. On the contrary, the central delamination does not substantially grow up to the global buckling displacement where an instantaneous small increase of delaminated area can be noticed.

These experimental observations on the delamination size changes during compressive displacements application can be easily related to the load displacement curves recorded during the load steps and shown in Figures 9 and 10, respectively, for the side and the central delamination configuration. Indeed the delamination growth experienced by the side 

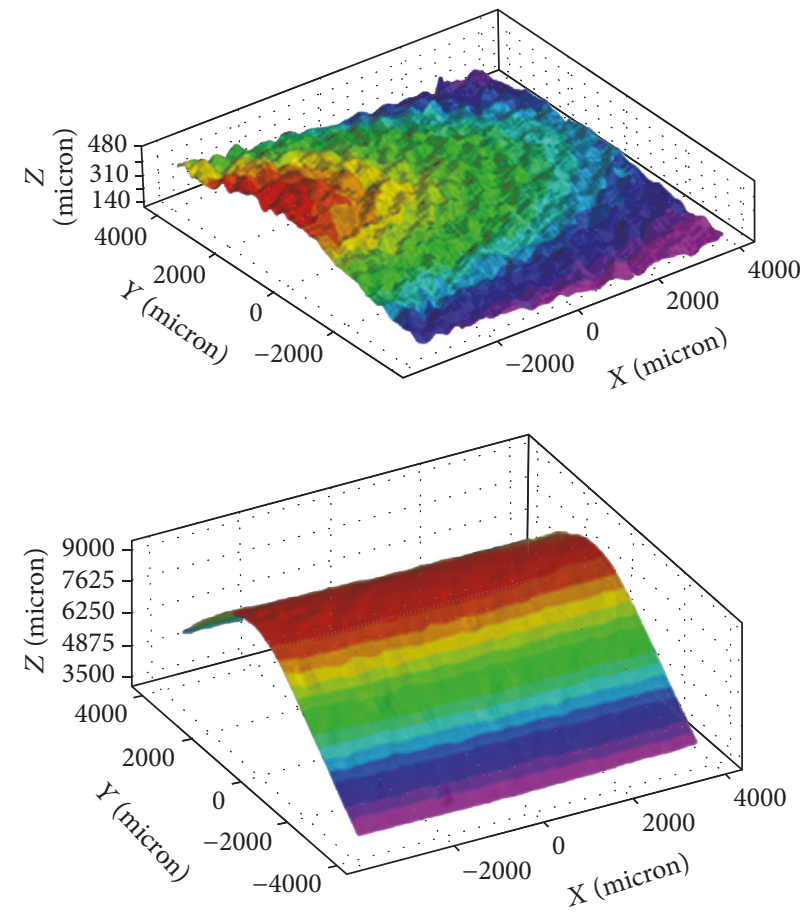

FIGURE 19: DIC: First and last step-3D plot-side delamination specimen.
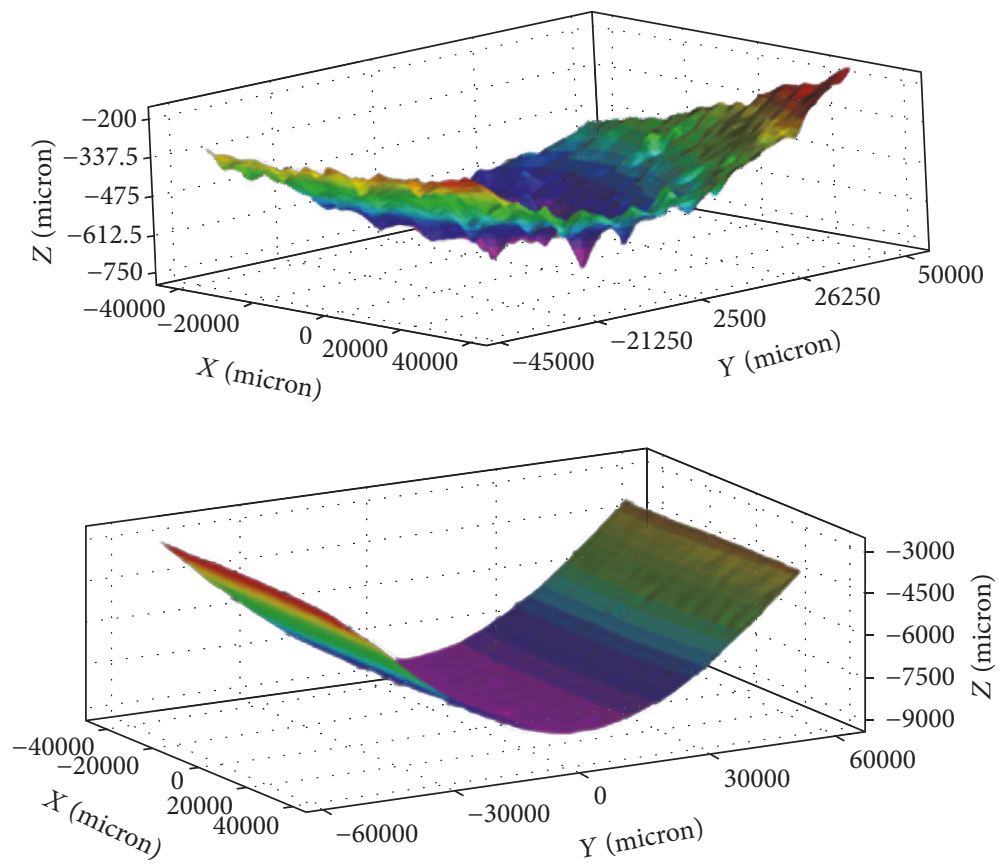

Figure 20: DIC: First and last step-3D plot-central delamination specimen.

delamination seems to influence the global stiffness and the global buckling load of the specimen (see Figure 9). On the other hand, the specimen with the central delamination, which does not propagate, seems to not experience stiffness and buckling load reductions. As an example, in Figure 24 the deformation of the specimen with central delamination at buckling is shown.
In the frame of this paper, due to need of elevated emissivity values for Lock-In performing, the DIC measurements have been taken on the opposite side with respect to surface closer to the artificial delamination. Hence, from the presented DIC measurements nothing can be derived concerning the delamination growth status. Indeed only the effects of delamination propagation on the global strain and 

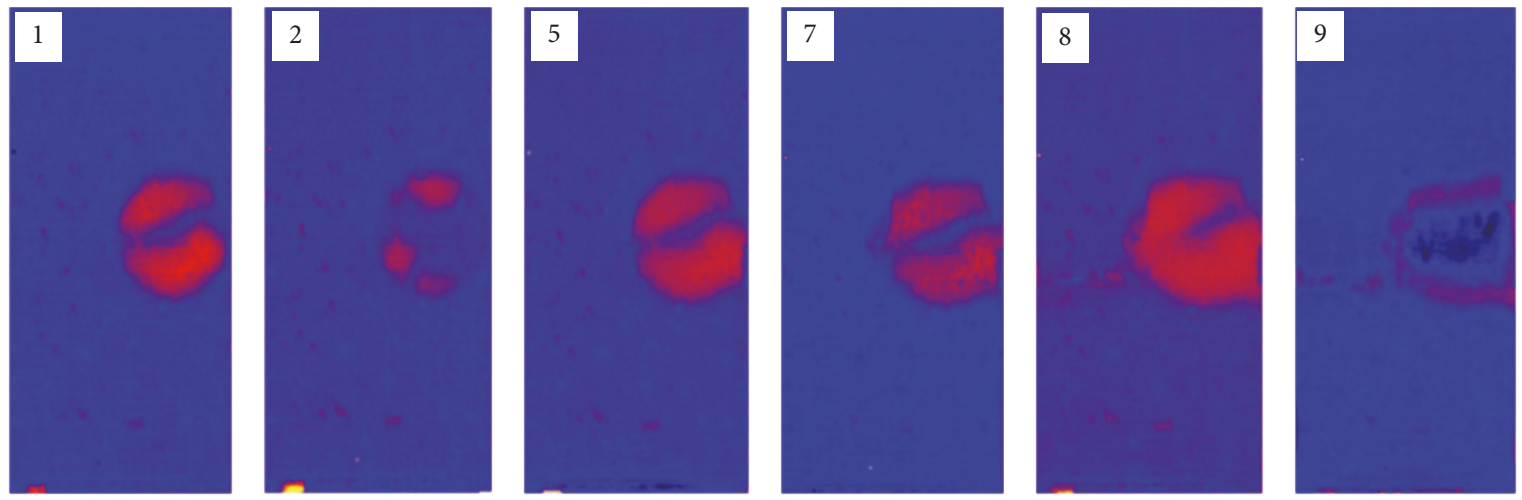

FIGURE 21: Delamination development-principal step-side delamination specimen.
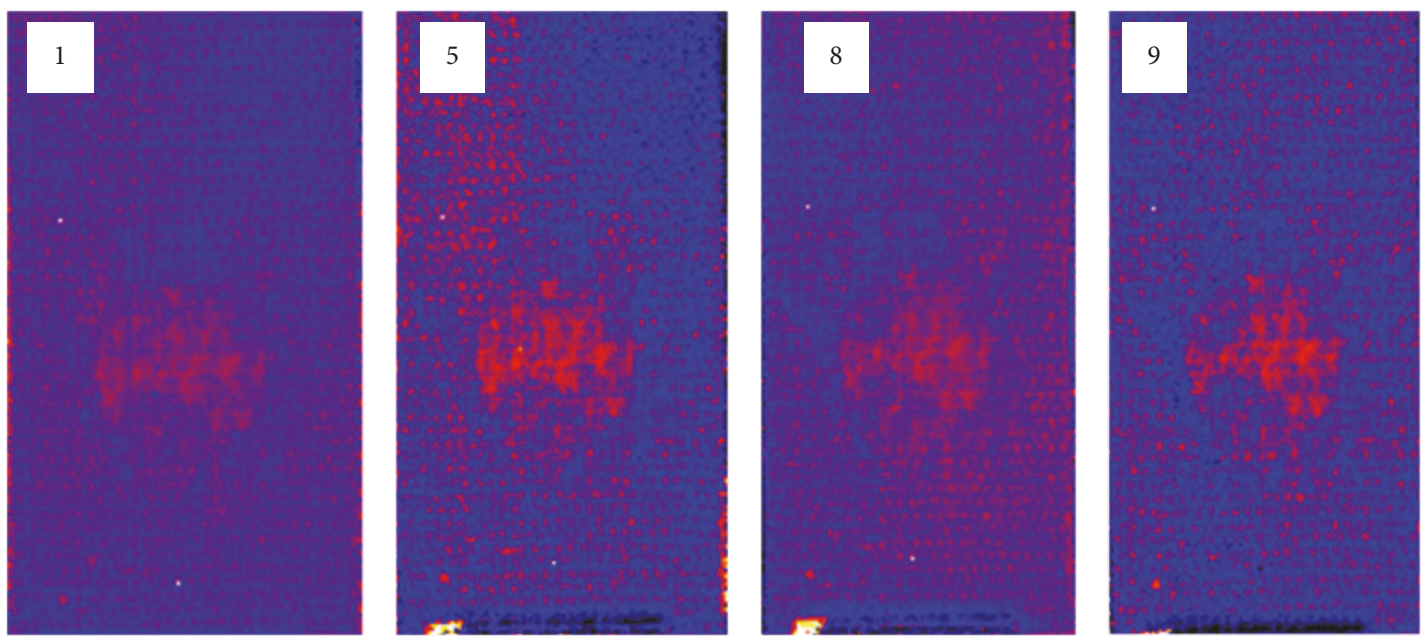

FIGURE 22: Delamination development-principal step-central delamination specimen.

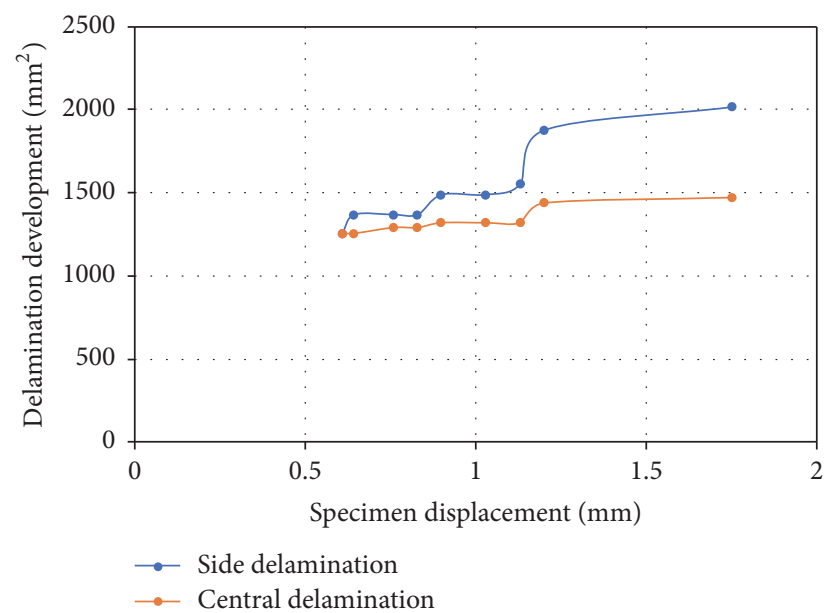

FIGURE 23: Delaminated area as a function of the applied compressive displacement, comparison between side and central delamination configuration.

out-of-plane displacements on the opposite side with respect to delamination have been evaluated. However, the details of

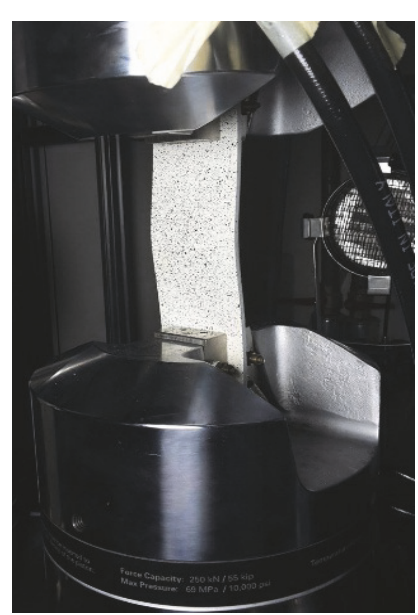

FIGURE 24: Specimen deformation at buckling, specimen with central delamination.

the obtained experimental results in terms of out-of-plane displacements (even in the first compressive steps when the delamination buckling can be relevant) suggest an alternative 
use for the Digital Image Correlation. As a matter of facts, the use of DIC measurements, taken on the delaminated surface, for its capability to determine with accuracy the strain and displacements in the delamination plane, could provide useful indirect no-contact information in terms of delamination buckling shape size.

\section{Conclusions}

In this paper, an experimental investigation on the delamination growth in composite plates under compressive load, by using two different experimental techniques (Infrared Thermography via Lock-In method and Damage Image Correlation), is presented. Two specimens with different delamination locations (side and central) have been investigated in order to understand the influence of delamination position on their global compressive behavior. The infrared camera has been used to monitor the internal damage development and the Digital Image Correlation (DIC) method has been used to obtain surface strain and out-of-plane displacements fields.

IRF and DIC measurements showed that, during test, the compressive behavior of the specimen with side delamination has been found mostly influenced by the delamination growth both in terms of stiffness and buckling load variations. On the contrary, no growth has been detected for the central delamination up to the final failure of the specimen. The influence of the local buckling of the delamination on the final surface strains and out-of-plane displacements distribution has been also appreciated for the two analyzed configurations. The obtained results suggest the use of DIC outputs, in terms of out-of-plane displacements, for the indirect measurement of the delamination size with a very easy implementation and without the need of contact with the specimen surface.

\section{Conflicts of Interest}

The authors declare that there are no conflicts of interest regarding the publication of this paper.

\section{References}

[1] L. Couchman and A. Mouritz, Modeling of Naval Composite Structures in Fire, Acclaim Printing Services, Victoria, Australia, 2006.

[2] S. Abrate, Impact on Composite Structures, Cambridge University Press, 1998.

[3] A. Raimondo and A. Riccio, "Inter-laminar and intra-laminar damage evolution in composite panels with skin-stringer debonding under compression," Composites Part B: Engineering, vol. 94, pp. 139-151, 2016.

[4] A. Riccio, M. Damiano, A. Raimondo, G. Di Felice, and A. Sellitto, "A fast numerical procedure for the simulation of inter-laminar damage growth in stiffened composite panels," Composite Structures, vol. 145, pp. 203-216, 2016.

[5] R. Borrelli, A. Riccio, A. Sellitto, F. Caputo, and T. Ludwig, "On the use of global-local kinematic coupling approaches for delamination growth simulation in stiffened composite panels," Composites Science and Technology, vol. 115, pp. 43-51, 2015.
[6] D. D. Symons and G. Davis, "Fatigue testing of impact-damaged T300/914 carbon-fibre-reinforced plastic," Composites Science and Technology, vol. 60, no. 3, pp. 379-389, 2000.

[7] A. A. Baker, R. Jones, and R. J. Callinan, "Damage tolerance of graphite/epoxy composites," Composite Structures, vol. 4, no. 1, pp. 15-44, 1985.

[8] G. Cricrì and M. Perrella, "Investigation of mode III fracture behaviour in bonded pultruded GFRP composite joints," Composites Part B: Engineering, vol. 112, pp. 176-184, 2017.

[9] G. Cricrì, M. Perrella, S. Sessa, and N. Valoroso, "A novel fixture for measuring mode III toughness of bonded assemblies," Engineering Fracture Mechanics, vol. 138, pp. 1-18, 2015.

[10] R. Citarella and G. Cricrì, "Three-dimensional BEM and FEM submodelling in a cracked FML full scale aeronautic panel," Applied Composite Materials, vol. 21, no. 3, pp. 557-577, 2014.

[11] G. Cricrì, M. Perrella, and C. Calì, "Experimental and numerical post-buckling analysis of thin aluminium aeronautical panels under shear load," Strain, vol. 50, no. 3, pp. 208-222, 2014.

[12] S. Sanchez-Saez, E. Barbero, R. Zaera, and C. Navarro, "Compression after impact of thin composite laminates," Composites Science and Technology, vol. 65, no. 13, pp. 1911-1919, 2005.

[13] A. Shipsha and D. Zenkert, "Compression-after-impact strength of sandwich panels with core crushing damage," Applied Composite Materials, vol. 12, no. 3-4, pp. 149-164, 2005.

[14] X. Wang, J.-F. Witz, A. El Bartali, and C. Jiang, "Infrared thermography coupled with digital image correlation in studying plastic deformation on the mesoscale level," Optics and Lasers in Engineering, vol. 86, pp. 264-274, 2016.

[15] G. Gaussorgues, Infrared Thermography, Chapman \& Hall, London, UK, 1994.

[16] S. Datcu, L. Ibos, Y. Candau, and S. Matteï, "Improvement of building wall surface temperature measurements by infrared thermography," Infrared Physics and Technology, vol. 46, no. 6, pp. 451-467, 2005.

[17] M. Poncelet, J.-F. Witz, H. Pron, and B. Wattrisse, "A study of IRFPA camera measurement errors: Radiometric artefacts," Quantitative InfraRed Thermography Journal, vol. 8, no. 1, pp. 3-20, 2011.

[18] M. A. Sutton, J. J. Orteu, and H. Schreier, Image Correlation for Shape, Motion and Deformation Measurements: Basic Concepts, Theory and Applications, Springer, New York, NY, USA, 2009.

[19] B. Pan, K. Qian, H. Xie, and A. Asundi, "Two-dimensional digital image correlation for in-plane displacement and strain measurement: a review," Measurement Science and Technology, vol. 20, no. 6, article 062001, 2009.

[20] B. Pan, A. Asundi, H. Xie, and J. Gao, "Digital image correlation using iterative least squares and pointwise least squares for displacement field and strain field measurements," Optics and Lasers in Engineering, vol. 47, no. 7-8, pp. 865-874, 2009.

[21] B. Pan and K. Li, "A fast digital image correlation method for deformation measurement," Optics and Lasers in Engineering, vol. 49, no. 7, pp. 841-847, 2011.

[22] B. Pan, J. Yuan, and Y. Xia, "Strain field denoising for digital image correlation using a regularized cost-function," Optics and Lasers in Engineering, vol. 65, no. 0, pp. 9-17, 2014.

[23] C. Cofaru, W. Philips, and W. Van Paepegem, "A three-frame digital image correlation (DIC) method for the measurement of small displacements and strains," Measurement Science and Technology, vol. 23, no. 10, article 105406, 2012.

[24] W. T. Kim, M. Y. Choi, and J. H. Park, "Diagnosis of defect points in materials using infrared thermography," Key Engineering Materials, vol. 297-300, pp. 2169-2175, 2005. 
[25] J.-H. Park, M.-Y. Choi, and W.-T. Kim, "Infrared thermography and modeling to the concrete deck with internal defects as a non-destructive testing," Key Engineering Materials, vol. 270273, pp. 938-943, 2004.

[26] G. Busse, D. Wu, and W. Karpen, "Thermal wave imaging with phase sensitive modulated thermography," Journal of Applied Physics, vol. 71, no. 8, pp. 3962-3965, 1992.

[27] O. Breitenstein and M. Langenkamp, "Lock-in contact thermography investigation of lateral electronic inhomogeneities in semiconductor devices," Sensors and Actuators, A: Physical, vol. 71, no. 1-2, pp. 46-50, 1998.

[28] http://thermosensorik.com/.

[29] S. Huth, O. Breitenstein, A. Huber, D. Dantz, U. Lambert, and F. Altmann, "Lock-in IR-thermography-a novel tool for material and device characterization," Solid State Phenomena, vol. 82-84, pp. 741-746, 2002.

[30] B. Pan and H. Xie, "Full-field strain measurement based on least-square fitting of local displacement for digital image correlation method," Acta Optica Sinica, vol. 27, no. 11, pp. 19801986, 2007.

[31] M. Wisnom, F. Pierron, C. Devivier, and D. Thompson, "Correlation between full-field measurements and numerical simulation results for multiple delamination composite specimens in bending," Applied Mechanics and Materials, vol. 24, pp. 109-114, 2010.

[32] C. Devivier, F. Pierron, and M. R. Wisnom, "Damage detection in composite materials using deflectometry, a full-field slope measurement technique," Composites Part A: Applied Science and Manufacturing, vol. 43, no. 10, pp. 1650-1666, 2012.

[33] L. Yang, P. Zhang, S. Liu, P. R. Samala, M. Su, and H. Yokota, "Measurement of strain distributions in mouse femora with 3D-digital speckle pattern interferometry," Optics and Lasers in Engineering, vol. 45, no. 8, pp. 843-851, 2007.

[34] F. Laurin, J.-S. Charrier, D. Lévêque, J.-F. Maire, A. Mavel, and P. Nuñez, "Determination of the properties of composite materials thanks to digital image correlation measurements," in Proceedings of the IUTAM Symposium on Full-Field Measurements and Identification in Solid Mechanics, pp. 106-115, July 2011.

[35] M. A. Caminero, M. Lopez-Pedrosa, C. Pinna, and C. Soutis, "Damage monitoring and analysis of composite laminates with an open hole and adhesively bonded repairs using digital image correlation," Composites Part B: Engineering, vol. 53, no. 24, pp. 76-91, 2013.

[36] G. Musotto, Digital Image Correlation: applicazione di tecniche convenzionali e sviluppo di soluzioni innovative per la stima e lincremento dellaccuratezza [M.S. thesis], Politecnico di Milano, Facoltà di Ingegneria Industriale, Corso di Laurea in Ingegneria Meccanica, 2012. 

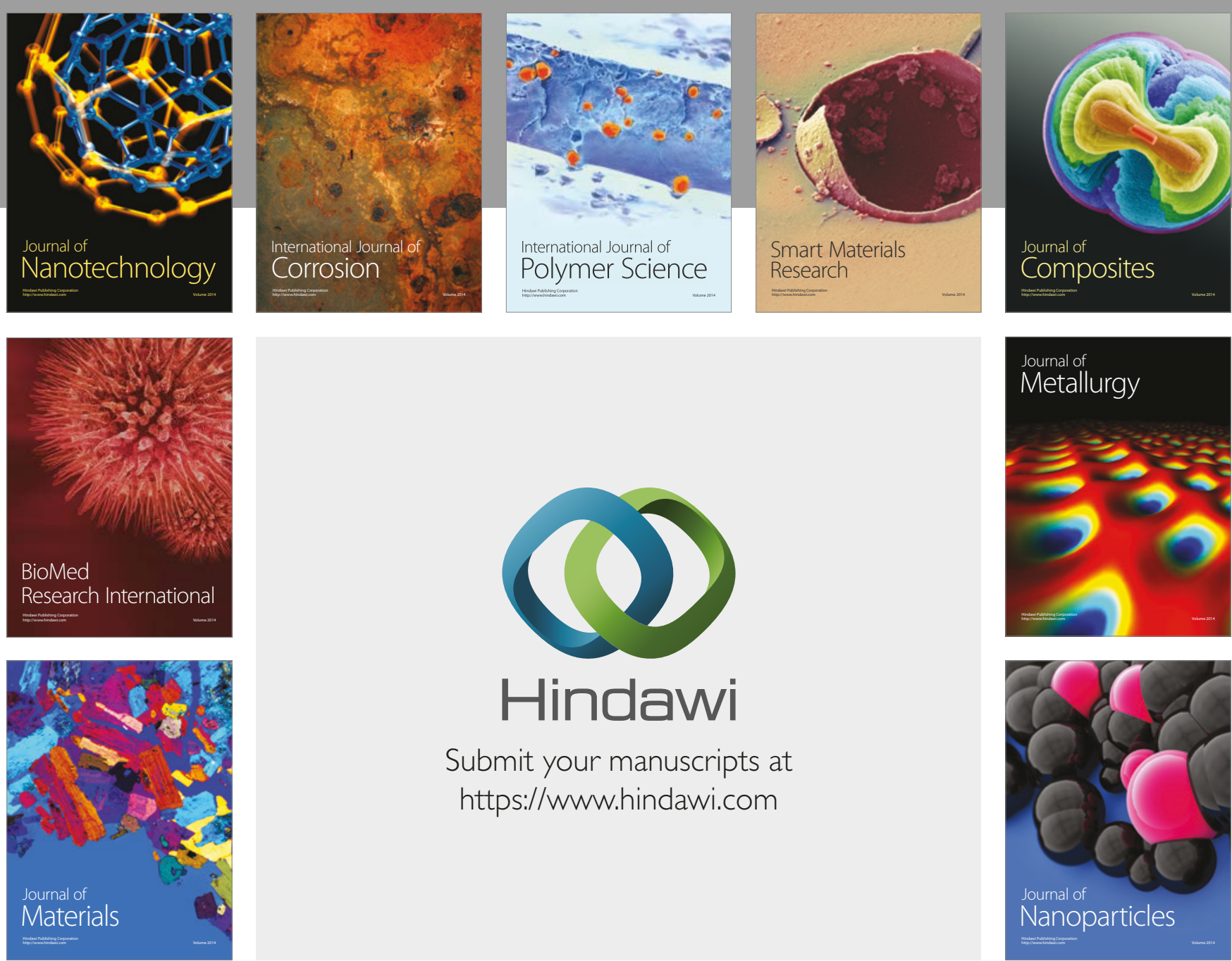

\section{Hindawi}

Submit your manuscripts at

https://www.hindawi.com
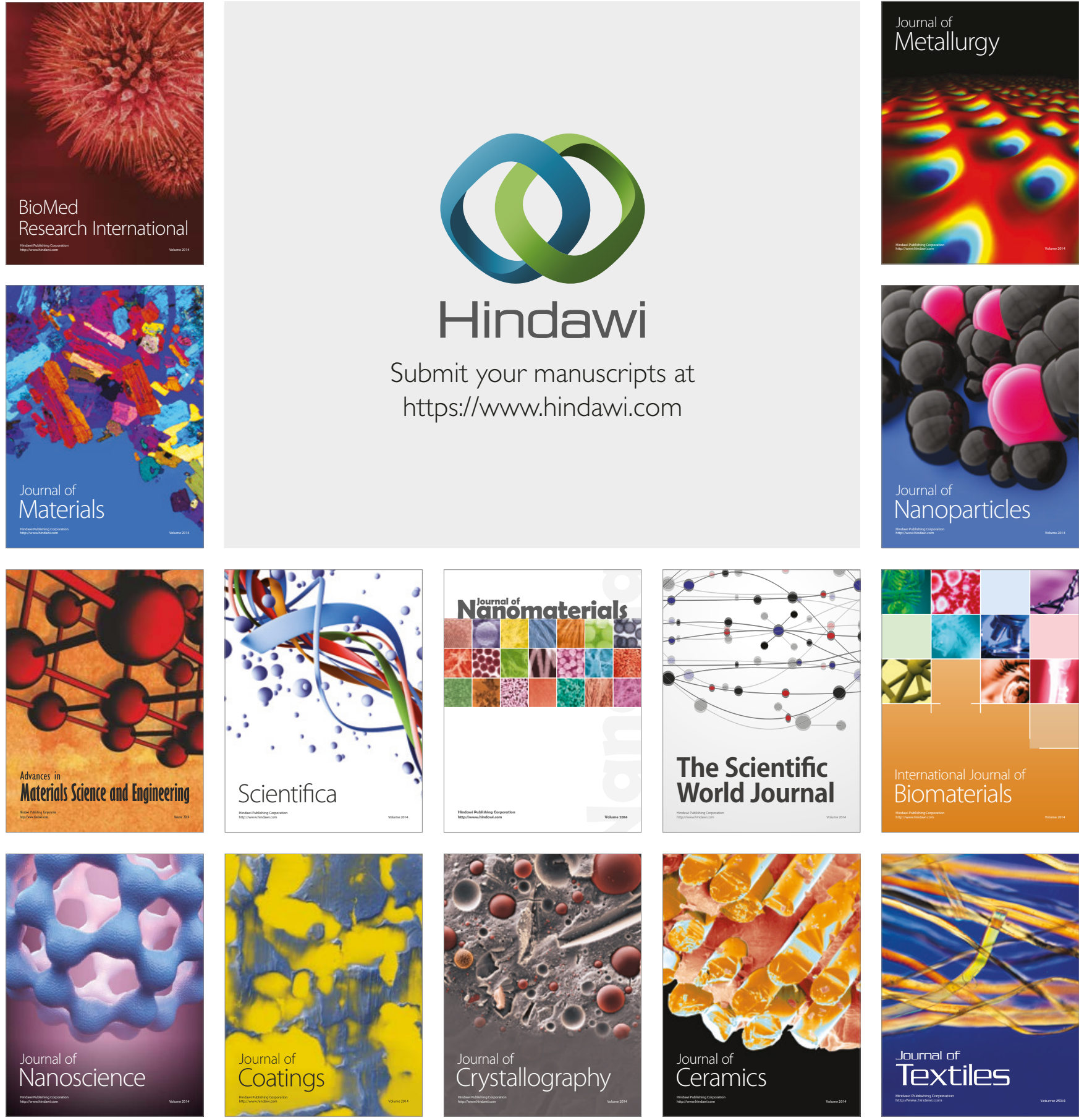

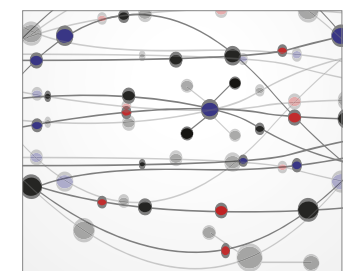

The Scientific World Journal
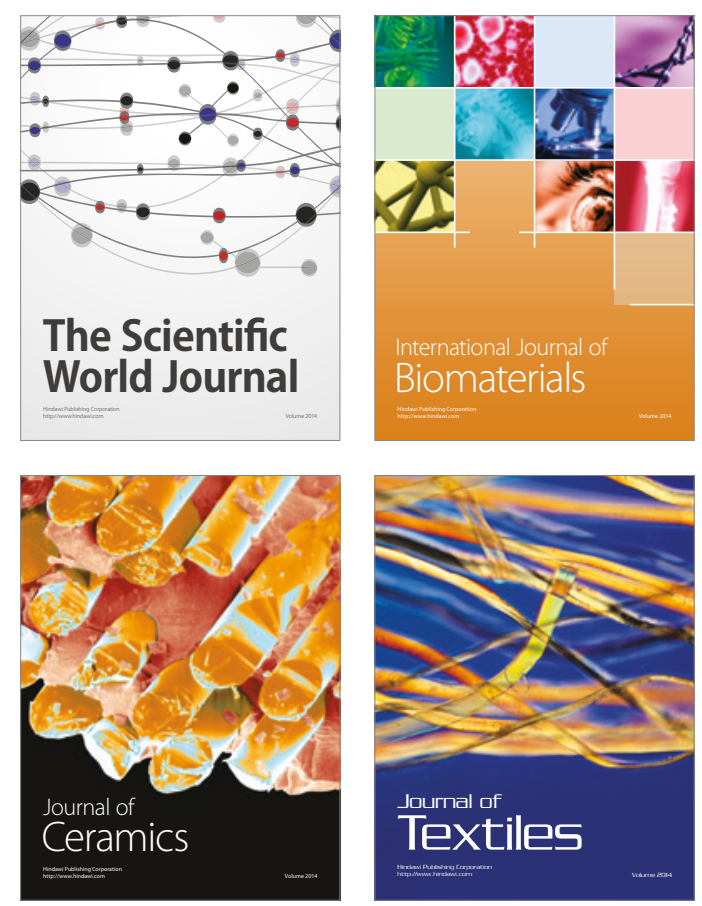